\title{
Mini-review: materials and modelling for organic photovoltaic devices
}

Olivier Doat, ${ }^{1 *}$ Bruno H. Barboza,${ }^{2}$ Augusto Batagin-Neto, ${ }^{3}$ Didier Bégué, ${ }^{1}$ Roger C. Hiorns ${ }^{1 *}$

${ }^{1}$ CNRS/Univ Pau \& Pays Adour, Institut des Science Analytiques et Physico-Chimie pour l'Environnement et les Materiaux, UMR5254, 64000, Pau, France.

${ }^{2}$ São Paulo State University (UNESP), School of Sciences, POSMAT, Bauru/SP 17033-360, Brazil

${ }^{3}$ São Paulo State University (UNESP), Campus of Itapeva, Itapeva/SP 18409-010, Brazil mail to: olivier.doat@outlook.com ; roger.hiorns@univ-pau.fr

\begin{abstract}
This short mini-review gives a simple and teacherly introduction to the field of materials and their modelling for the active-layer in organic photovoltaic devices. It gives a perspective on past work and a summary of the current state-of-the-art. Given the extremely fast changes on-going in this field, it is hoped that this document will serve both as a timely snap-shot and a pedagogical entry point to this fascinating subject. Furthermore, an example is given of how modelling can enhance the understanding of the structures and qualities of materials using a leading low band-gap polymer donor and non-fullerene acceptor pair (PM6 and Y6).
\end{abstract}




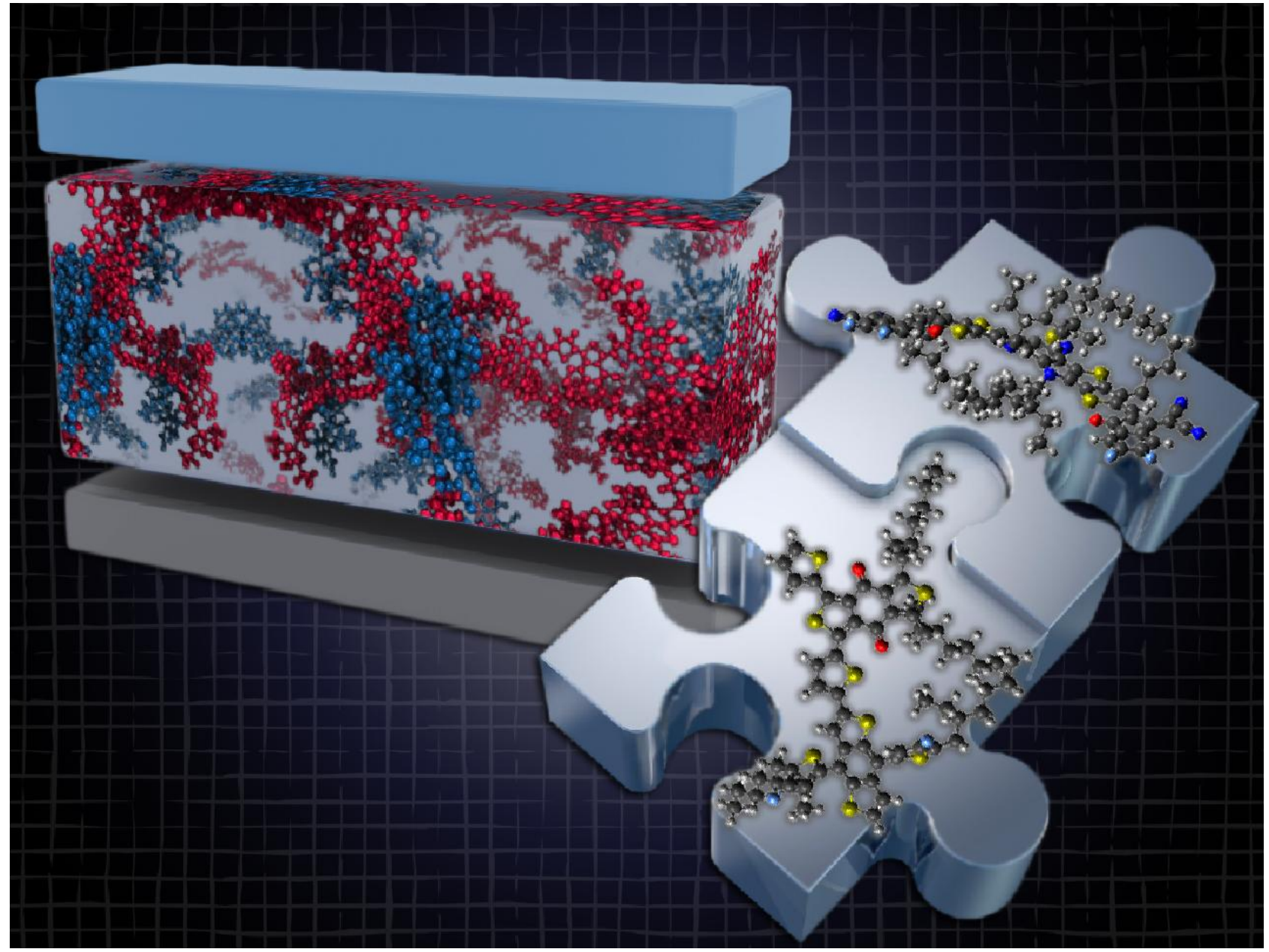

This teacherly mini-review gives an overview of the development of the active layer in organic photovoltaic devices and a snapshot of current activities in this extremely dynamic field. 


\section{Introduction}

With accelerating increases in energy consumption that are often locked to fossil-sourced pollution, many scientists are looking for ways to collect energy from nature. Harvesting the radiative energy provided by the sun is an attractive idea since it is the most abundant and carbon neutral energy source available on Earth. ${ }^{1}$ Since their discovery, solar panels have consistently improved their efficiencies, both in the lab and in industry, and have considerably diversified, with many different types appearing over the last few decades. While many are inorganic, and outside the scope of this mini-review, we will focus on the state of the art of polymer-based organic photovoltaics (OPVs) which have gone through a startling and recent growth in efficacy. ${ }^{2}$ When compared to their inorganic counterparts, they possess now only slightly lower efficiencies but display numerous advantages, such as non-toxicity, exceptional energy payback times, ${ }^{3}$ low weights and flexibility, low-temperature processing, and they are made from abundant materials. OPV panels can be easily tuned with various shapes and colors and weights, depending on their encapsulation. Moreover, they are less susceptible than inorganic devices to the impact of the angle of the incoming light and they support low level light as their limiting factor is internal resistance rather than the amount of incoming light. ${ }^{4}$ All these qualities should facilitate their integration into buildings and urban designs. ${ }^{5}$ It is easy to imagine cities filled with OPV modules.

\section{Generalities of $\mathrm{OPV}$}

To better understand how to improve OPV efficiencies, it is essential to understand the photocurrent generation mechanism and the losses behind it. The general concept of photocurrent generation is that when a photon hits a photovoltaic module, it excites an electron and this electron moves through the device and the circuit to relax to its initial state. 
Behind this simple concept, a much more complex one is involved which has been optimized by employing various materials and device architectures. While there is a wide range of device structures, such as 'normal' and 'inverted', the classic device can be considered as that shown in Figure 1, composed of six layers. There is an active layer, where the generation begins, sandwiched by two blocking layers (also called selective layers) themselves sandwiched by the electrodes, with one of them transparent to let the light pass through. Each layer plays a specific, important role in the photocurrent generation mechanism. There is also a substrate layer which is made of transparent glass or plastic, typically poly(ethylene terephthalate) (PET), ${ }^{5}$ giving the mechanical strength of the module and, importantly, protecting it from water and air. Often other coatings and layers are used, such as anti-UV barriers, poly(carbonate) supports for building integration and so on.

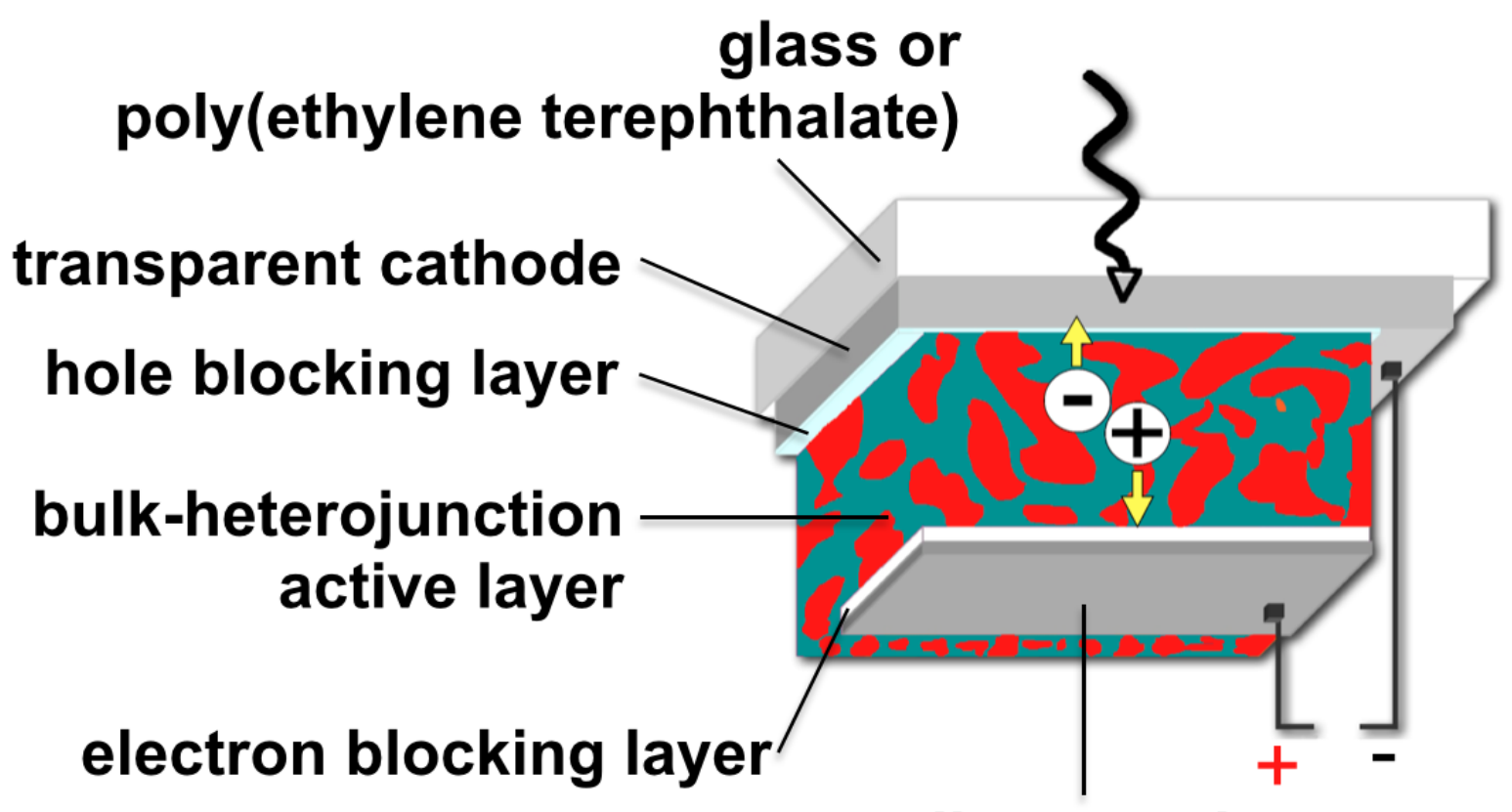

silver anode

Figure 1. Schematic of an 'inverted' organic photovoltaic cell containing an active layer based on a bulk-heterojunction.

The generation of a photocurrent starts with the process shown in Figure 2. In (a) there is a photo-excitation of an electron in the ground state of the active layer, creating an electron- 
hole pair called an exciton. In (b) the exciton is then split at an interface between a donor and acceptor in an extremely fast process leading to a carrier transfer state. Finally, (c) the charges are separated, and the electrons move towards the cathode and the holes towards the anode. ${ }^{6}$

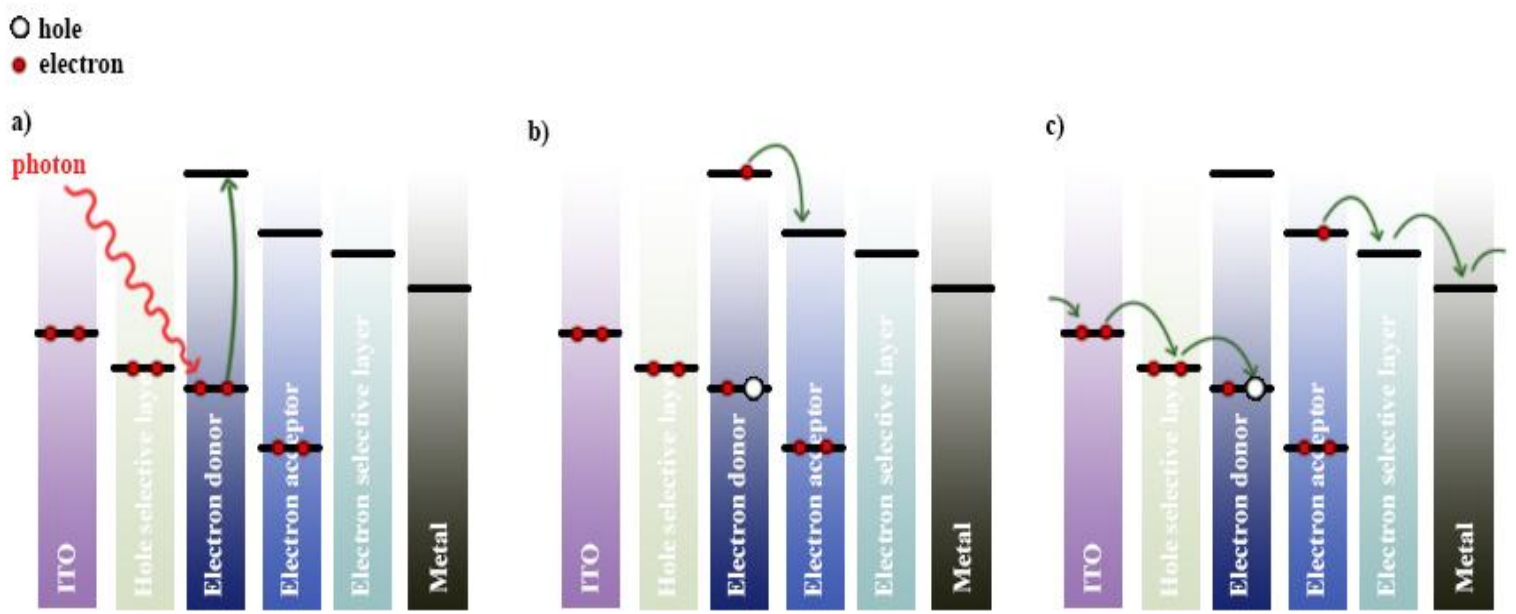

Figure 2. Photocurrent generation mechanisms in an OPV. (a) An incoming photon excites an electron in one of the materials in the active-layer; in this case in the donor. (b) An extremely fast transfer of the electron to a nearby acceptor, within the radius of the exciton pathway length, "rescues" the exciton from coalescence. And finally (c) a cascade of steps permits the electron and hole to find stable states via doing work in the outside circuit.

Current generation can fail at each of these steps. When an incoming photon fails to create the exciton, it generates photon losses. The ratio of collected electrons over the quantity of incident photons determines the external quantum efficiency (EQE). It is typically near to or greater than $80 \%{ }^{7}$ When the exciton recombines before the charge transfer state, we have what is generally termed exciton losses. Deeper details about the charge transfer state and the physical explanation behind it can be found in the review of Liu et al. ${ }^{8}$ When recombinations occur before the charge-carriers reach the electrodes, the losses are called, not unsurprisingly, charge-carrier losses. The charges can be lost by recombinations of electrons with their respective holes (geminate recombinations) or with holes generated from a different exciton 
(non-geminate recombinations). Other losses include those arising from non-radiative processes, such as energy being lost by the creation of a phonon.

Looking at the process of exciton splitting, we can see that the two charges that make up an exciton are bound by a binding energy $E_{\mathrm{B}}$ which is defined by:

$$
E_{B}=\frac{q^{2}}{4 \pi \epsilon_{0} \epsilon_{r} r}
$$

in which $q$ is the charge of an electron, $\varepsilon_{0}$ the vacuum permittivity, $r$ the distance between the hole and the electron and finally $\varepsilon_{r}$ is the permittivity of the material.

In inorganic modules, the strong interaction of the commonly employed metalloids, such as silicon, induces a high permittivity $(\sim 11)$ and an important delocalization of the exciton. This results in a very low $E_{\mathrm{B}}$ (of the order of few meV) which makes it easy to split at room and working temperatures. However, in the case of OPVs, the low intermolecular interactions lead to a low value of $r$ and a relatively low $\varepsilon_{r}$ (about 3-4) ${ }^{9}$ which means a high $E_{\mathrm{B}}$, of about $0.3 \mathrm{eV} \cdot{ }^{10}$ Note that this value can vary widely depending on the nature of the materials used, and indeed can be reduced. ${ }^{11}$ The thermal energy that is available at room temperature $\left(k_{\mathrm{B}} T\right)$ is $25 \mathrm{meV}$ which is clearly not enough to dissociate the two parts. These differences can be seen in Figure 3.

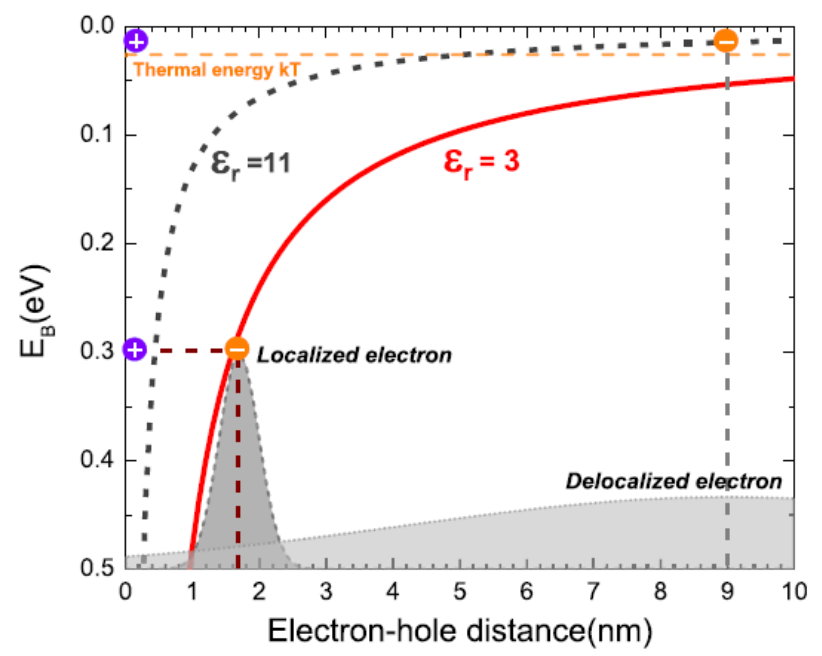

Figure 3. Evolution of the exciton binding energy depending on the electron-hole distance according to the permittivity of the material. Reprinted with permission from reference 6 . Copyright Elsevier 2020. 
To overcome this barrier to charge separation, the solution was found by Tang in 1986. ${ }^{12}$ The active layer of an OPV device is made of two materials that have different electrochemical potentials. The one with the lowest ionization potential is called the electron donor and the other one is the electron acceptor. This difference creates an offset energy which is, for a well-designed material, high enough to split the exciton. Accordingly, this potential difference should be at least equivalent to the binding energy of the exciton. The splitting mechanism can then occur in two ways: (1) the exciton is created in the donor, then the electron will be transferred to the lowest unoccupied molecular orbital (LUMO) of the acceptor, as shown in Figure 1; (2) the exciton is created at the acceptor, and the hole is transferred to the highest occupied molecular orbital (HOMO) of the donor. In both mechanisms, the exciton is split at the donor-acceptor interface. This implies that not only the absorption of the donor is important, but also the absorption of the acceptor should be high in order to maximize the EQE. Of course, only a photon with the same wavelength as the absorption of the active layer will be able to excite an electron and will potentially induce a current. That is why it is important to design donor and acceptor materials in a way that they have complementary absorption ranges, optimizing the coverage of the solar spectra. After being split at the junction, the electron-hole pair remain close and can still recombine if they cannot reach the electrodes quickly, leading to charge carrier losses. The study of the morphology and the carrier mobility in the active layer are important to reduce these losses and will be discussed latter on.

The power conversion efficiency (PCE) of a cell is given by the following equation:

$$
\eta=\frac{J_{S C} \cdot V_{o c} \cdot F F}{P}
$$

where $P_{\text {in }}$ is the input power provided by the sun, $F F$ is the fill factor, determined with the curve of the current density as a function of the voltage as seen in Figure 4. It represents the 
maximum attainable power from an OPV and is the ratio of the actual maximum power out over the ratio of the maximum theoretical power out as so:

$$
F F=\frac{I_{P \max } V_{P \max }}{I_{S C} V_{O C}}
$$

$J_{s c}$ is the short-circuit current density, measured against a circuit with no resistance, and is proportional to the ability of the active layer to absorb light, the photon flux of the sun, and the exciton dissociation efficiency. $V_{\mathrm{oc}}$, the open-circuit voltage, represents the maximum possible voltage attainable from a device, measured against an infinitely, or in reality, an extremely high value resistor. It is directly related to the difference between the HOMO of the donor and the LUMO of the acceptor, as this is the theoretical limit for providing a potential difference. ${ }^{13}$ It is often reduced by interfacial resistances inside the device, and indeed, measuring the difference between the $V_{\text {oc }}$ can provide essential clues about defects and ways to improve a device at its interfaces. Unfortunately, there is a duality in the relationship between the $J_{\mathrm{sc}}$ and $V_{\mathrm{oc}}$ values which hampers advances in device improvements. To increase $J_{\mathrm{sc}}$, one can reduce the band-gap of the donor by raising its HOMO. But as the gap between the HOMO of the donor and the LUMO of the acceptor is directly linked to the value of the $V_{\text {oc }}$, the larger this gap is, the higher the $V_{\text {oc }}$ will be. This means that less light is able to promote excitonic states, and therefore there is a reduction in the current. Similarly, increasing the HOMO of the donor will increases the value of $J_{\mathrm{sc}}$, but will reduce the $V_{\mathrm{oc}}$. Another relationship that confuses the matter is that when the LUMO of the acceptor is raised to reduce the gap between it and the LUMO of the donor, then the offset energy brought by the junction is reduced and the $V_{\mathrm{oc}}$ further improved. An illustration of this duality is shown in Figure 5. 


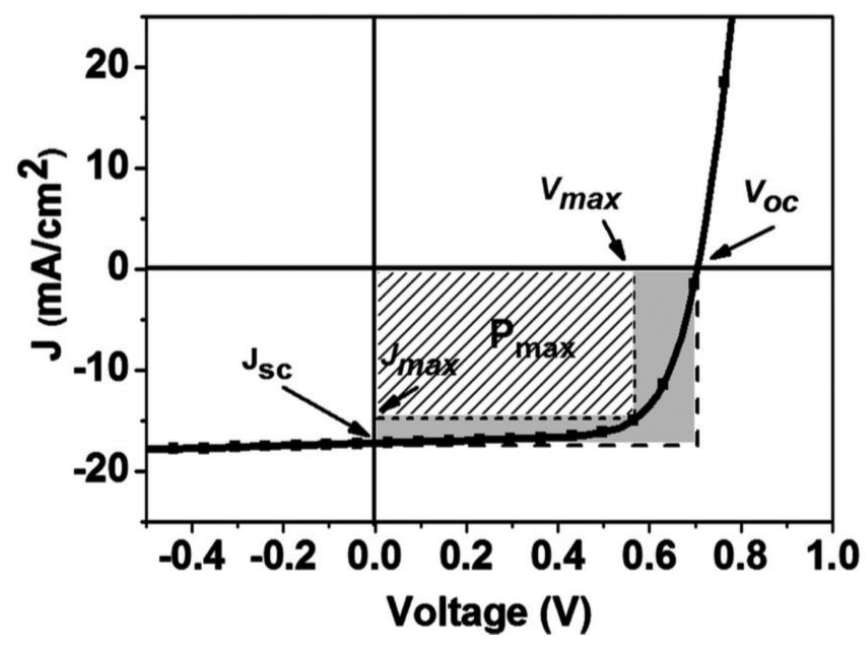

Figure 4. A typical plot of current density against measured tension for an OPV. The fill factor is represented by the area of dashed lines. Reprinted with permission from reference 14 . Copyright 2015 American Chemical Society.
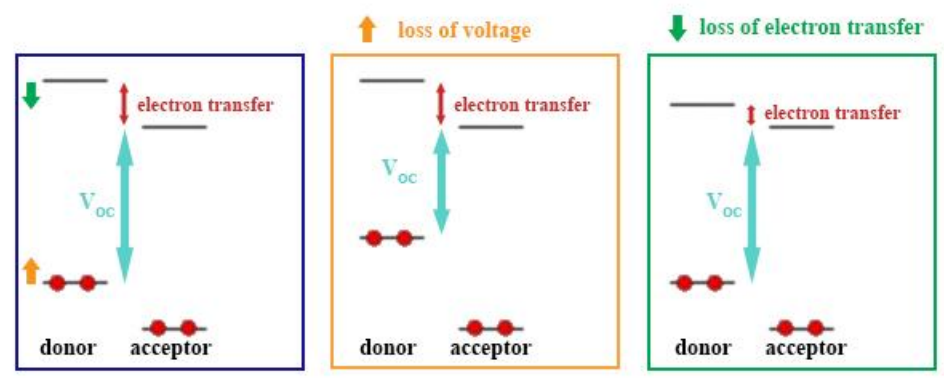

Figure 5. Evolution of the $V_{\text {oc }}$ and the electron transfer depending on the band gap of the donor.

\section{The active layer}

Each layer has its importance and can massively influence the overall efficiency. To focus this work, we will concentrate on the central active layer. The reader can find excellent reviews on electron and hole-transport layers, ${ }^{15-17}$ and a key transparent material, poly(3,4-ethylene dioxythiophene)-compl-poly(styrene sulfonate) (PEDOT:PSS) ${ }^{18}$ in the literature. The transparency of the layers between the light source and the active layer, light diffraction, plasmonic effects, to identify but a few parameters, all play a role in determining the outgoing current. Particularly important though, as identified above, are the impact of the energy levels of the polymers and molecules involved in the electronic transfers within the active layer to 
the electrodes. In order to accelerate new discoveries, computational methods can be employed to select best targets for syntheses.

Computational steps are very important for efficient researches. It can prevent the waste of material and time by predicting if the molecule aimed would be worth synthesizing and studying. It helps understanding phenomena that are difficult to predict and can help improve them for further research. For example, in their paper, Lopez et al. ${ }^{19}$ have combined computational methods with machine learning to design molecules that would be good acceptor candidates in OPV modules. However, in general, computational methods are not yet completely reliable as they are unable to take into account complete morphological and environmental perturbations, but nevertheless methodologies have been developed to give best approximations with respect to the system studied, applying various basis-sets chosen for their adaptability to the (macro)molecules under consideration. Most of the references from here on employ computational chemistry in their research to explain working mechanisms or predict optimized materials and devices. Near the end of this review we will show an example of how modeling can be used with a current standard-bearer system.

\subsection{Electron donors}

In the years following the discovery of a light-stimulated fast electron transfer from a polymer to a fullerene derivative, namely phenyl $\mathrm{C}_{61}$ butyric acid methyl ester (PCBM), by Sariciftci et al. in $1992,{ }^{20}$ the chemistry and modelling of the donor polymers received the greatest attention as they were the simpler to modify. Fullerene had only been discovered seven years

before, ${ }^{21}$ and as a result its chemistry was not so mature, and it remained expensive thus limiting its study. Donors can be divided in two categories, polymers and small molecules. 


\subsubsection{Conjugated polymers}

The first polymers used in an OPV device were electrochemically grown poly(thiophene)s back in $1984 .^{22}$ However, it was the aforementioned discovery of electron transfer between a thin film of a polymer and a thin film of PCBM sandwiched between two electrodes that gave real impetuous to the research field. The subsequent discovery of a bulk-heterojunction in which both donor and acceptor were intimately mixed in the active-layer in $1995,{ }^{23}$ gave rise to an extraordinary growth of works performed in the area, which has been well reviewed. ${ }^{24,25}$ Initially, poly(1,4-phenylene vinylene) (PPV) was the polymer of choice. It is yellow, highly crystalline, and fluorescent polymer that can be easily synthesized by a variety of routes. $^{26}$ The first use of PPV with PCBM gave a low $0.04 \%$ efficiency ${ }^{22}$ due to the bilayer nature of the device, and developments were hampered by the low solubility of the polymer. Considerable improvements came about through side-chain engineering of PPV to give poly[2-methoxy-5-(2-ethyl-hexyloxy)-1,4-phenylene-vinylene] (MEH-PPV) which increased its solubility and miscibility with $\mathrm{PCBM}^{27}$ even though it suffered from oxidative stability. ${ }^{28}$ Greater control over the morphology of the active-layer by using various casting solvents such as toluene and chlorobenzene with poly[2-methoxy-5-(3',7'-dimethyloctyloxy)-1,4phenylenevinylene] (MDMO-PPV) by Shaheen et al. further raised the efficiency to $2.5 \%{ }^{29,30}$

To form an exciton in the polymer, the energy of the incoming photon needs to be greater than or equal to the gap between the HOMO and LUMO of the polymer. As the gap is reduced, more photons have enough energy to make excitons, thus having a direct and proportional impact on the produced current. A straightforward way of reducing the gap is to increase the degree of conjugation in the polymer. ${ }^{31,32}$ An increase in the number of overlapping $\pi$-orbitals raises the HOMO and lowers the LUMO. Importantly, the overlap of $\pi$-orbitals is maximized by flattening the polymer backbone, as the orbitals have the highest possible symmetry. A straighter backbone therefore leads to a higher HOMO and a lower 
gap. ${ }^{33}$ Various methods have been used to rigidify polymers including the fusion of rings and the use of bridging atoms. Increasing the quinoidal character of a system can also contribute to its planarity ${ }^{34}$ and help reduce the band gap, ${ }^{35}$ as shown in Figure 6. Because of these reasons, polymers made from thiophenes were found to be highly successful, due to their tendency towards quinoidal forms.

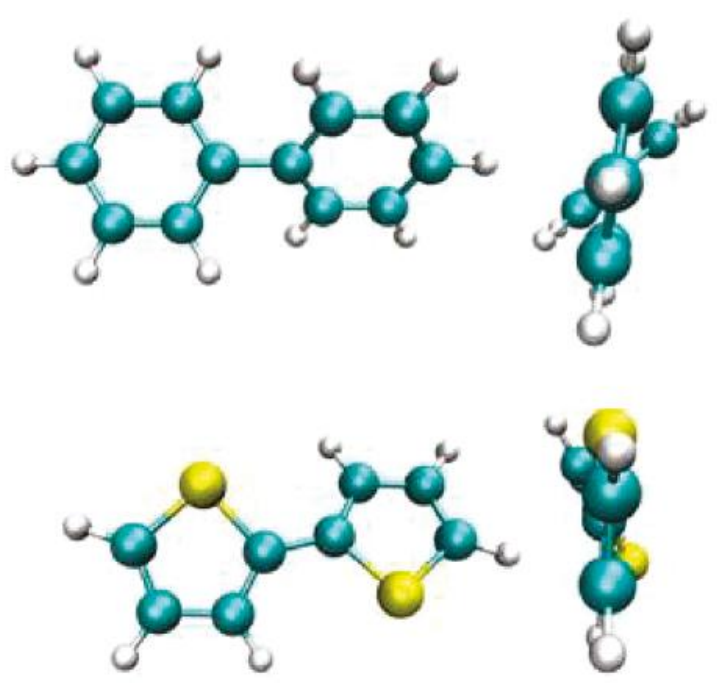

Figure 6. Illustration of the effect of the quinoidal character on the planarity of the backbone. Reprinted with permission from reference 34. Copyright 2014 American Chemical Society.

An archetypical polymer, poly(3-hexylthiophene) (P3HT), Figure 7, was for at least a decade the most common electron donor because of its facile synthesis, ${ }^{36}$ low cost and exceptional efficiencies, up to around 5\%, when used with PCBM. ${ }^{37}$ P3HT has a very straight chain, and a strong tendency to crystallize which is enhanced by the hexyl chain which interdigitates between adjacent chains. ${ }^{38}$ This characteristic could be further increased by careful annealing of the active-layer, ${ }^{39}$ or by the addition of small molecules such as diiodooctane. ${ }^{40}$ The latter, however, can impact heavily on the stability of the device, ${ }^{41}$ unless post-production treatments are used. ${ }^{42}$ 


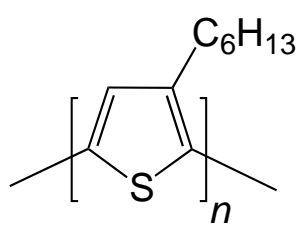

Figure 7. The chemical structure of P3HT.

Conjugation is not the only solution when it comes to reducing the band gap. When two molecules with different molecular orbitals (MO) are fused, the orbitals with the same symmetries create two new orbital levels, one lower and one higher, as shown in Figure 8. This can be applied to polymers by generating alternating copolymer structures from two different compounds, one with a higher HOMO (a donor part) and one with a lower one (an acceptor) to yield the so-called low band-gap polymers. ${ }^{43}$ By changing or making modifications to comonomers, the gap can be tuned and optimized, for example the addition of electron-donating alkyl side-chains and electron-withdrawing halides at specific positions can reduce the HOMO to improve the $V_{\mathrm{oc}}{ }^{44}$ Polymers that have been particularly successful include the benzodithiophene (BDT) comonomer, such as poly(benzodthiophene-1,3-bis(5bromothiophen-2-yl)-5,7-bis(2-ethylhexyl)-4H,8H-benzo[1,2-c:4,5-c']dithiophene-4,8-dione) (PBDTBDD), ${ }^{45}$ as shown in Figure 9. Note that the quinoidal effect mentioned above again here has a strong influence in straightening the backbone. 


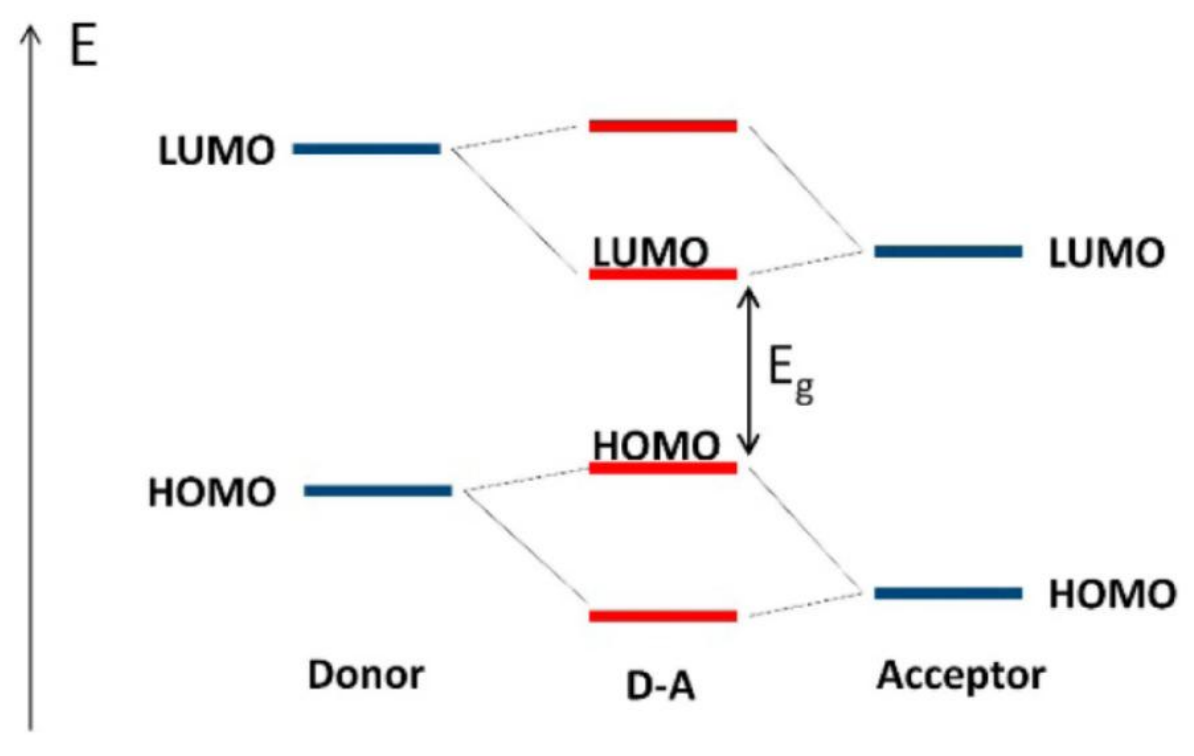

Figure 8 Illustration of HOMOs and LUMOs from donor and acceptor comonomers combining to deliver a so-called D-A molecule with a reduced band-gap. Reprinted with permission from reference 14. Copyright 2015 American Chemical Society.
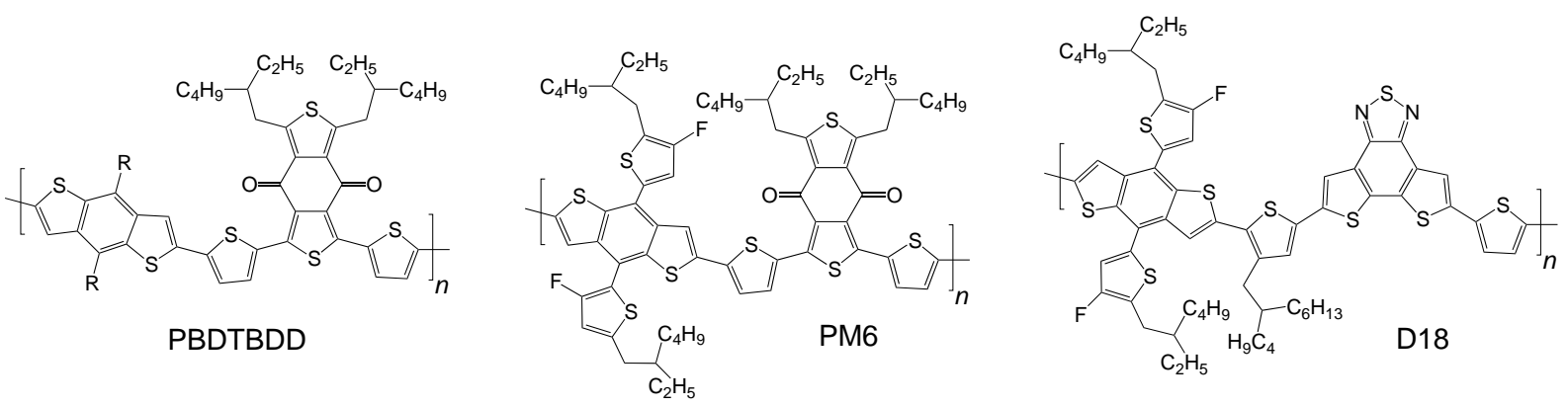

Figure 9. Key low-band gap polymers that have enabled high efficiencies.

Recent papers have used derivatives such as PM6 (Figure 9) to record efficiencies, for example 17.3\%, reached by Meng et al. ${ }^{46}$ in 2018 in a tandem device. An even higher efficiency of $18.22 \%$ was reached by Liu et $a l .{ }^{47}$ in a single layer device with D18 as a polymer donor that incorporated a dithieno[3',2':3,4;2",3":5,6]benzo[1,2-c][1,2,5]thiadiazole heterocyclic fused-ring acceptor. More recently, $18.56 \%$ have been reached with this polymer. ${ }^{48}$ Excitingly, the $20 \%$ barrier has been broken using a $1 \mathrm{~cm}^{2}$ cell, although it was for low-light levels indoors. ${ }^{49}$ 


\subsubsection{Small molecules}

The seminal and pioneering work performed by Tang in 1986 demonstrated the photovoltaic effect for vacuum-deposited bilayers of small molecular donors and acceptors. ${ }^{12}$ Respectively they were a copper phthalocyanine and a perylene derivative, and together with an indium oxide interlayer and silver electrodes gave an efficiency of around $1 \%$. While the difference of size with respect to polymers is clearly apparent, small molecules have the advantages of being prepared, generally speaking, with more uniform structures than polymers, and generally exhibit higher solubilities or can be vacuum treated. However, they do not have the strength and flexibility that polymers' structures confer by way of their extensive covalent bonding, and neither do they have the long-range conjugation that can enhance chargemobilities. An early example of a good molecular donor is shown in Figure 10, made by Roquet et al. ${ }^{50}$ and one of an exceptional series of 3-dimensional structures which attempted to move current more easily through the active layer. ${ }^{51}$ Engineering of diketopyrrolopyrrole to yield 3-D structures more recently delivered, with a polymer acceptor, efficiencies of about $4 \% .^{52}$ 


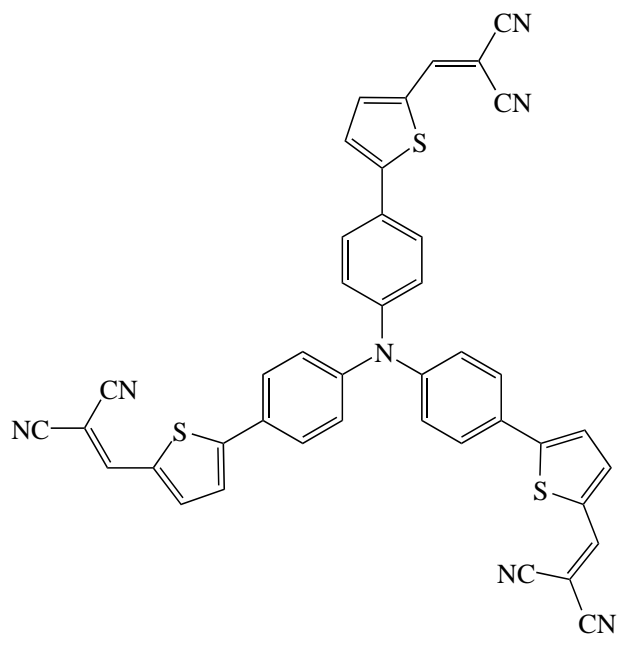

Figure 10 Molecular structure of triphenylamine derivative combining thienyl and dicyano groups. ${ }^{50}$

The use of alternated donor-acceptor (D-A) blocks in small planar molecules is also possible, but like the 3-dimensional systems, and opposed to the polymer, the alternation is only over a few units. These are commonly called ladder-type or push-pull molecules. They show high electron mobilities due to enhanced intramolecular charge transfer and their aggregation can be controlled by adding side-chains that act as spacers between the stacked molecules. Nevertheless, fewer examples of these systems exist with respect to those based on polymers, perhaps due to expectation that they are unable to transfer charges along long chains, like polymers. Good examples of push-pull donor are the D-A-D-A-D molecule made by Sun et al..$^{53}$ and the A-D-A by Zhou et al. ${ }^{54}$ that reached $6.7 \%$ and $8.12 \%$ efficiencies, respectively. Both are shown in Figure 11. The area has since been well reviewed by Ilmi et $a l .{ }^{55}$ and even more recently, $14 \%$ efficiencies have been demonstrated with all-smallmolecule organic solar cells by exploiting a high degree of molecular planarity, thus enhancing stacking and intermolecular $\pi-\pi$ charge-transfer. ${ }^{56}$ 

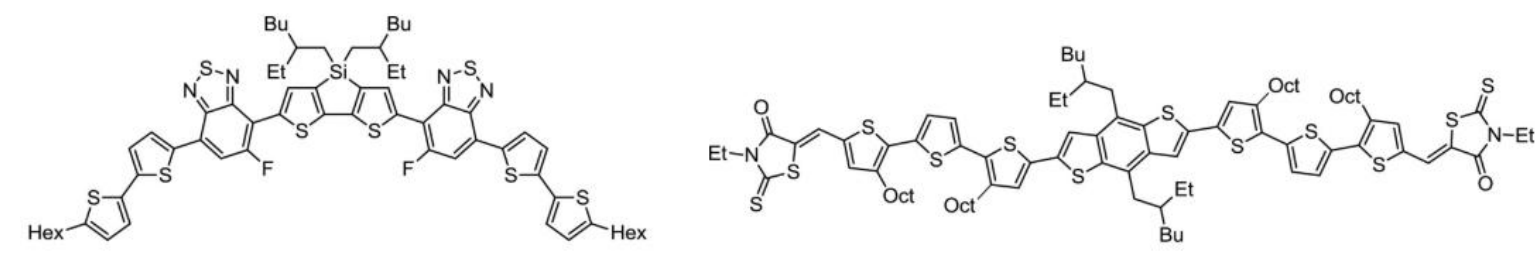

Figure 11. Molecular structure of DTS(PTTh2) $2^{53}$ and DR3TBDTT, ${ }^{54}$ respectively, left and right.

To sum, the advantages of these small molecules are that they are easily tuned, with very specific modifications being feasible, such as changing substituents in the end-groups to modify the optical and electronic properties, and they possess strong chromophoric properties. Charge mobilities are reasonably high, typically up to around $10 \mathrm{~cm}^{2} \mathrm{~V}^{-1} \mathrm{~s}^{-1}$. However, they are extremely sensitive to their molecular packing and impurities, and lack the mechanical strength and processing ease of polymers. By comparison, polymers currently show similar charge mobilities, so while their conjugation is segmented, ${ }^{57}$ and their charge mobility very much controlled by intra-chain hopping, ${ }^{32}$ it is expected that better exploitation of throughchain conjugation will open up mobilities of an order or so higher. An excellent review dissecting the impact of structure on charge transport is given in reference 58.

\subsection{Electron acceptors}

Current research imperatives for electron acceptors include controlling the HOMO and LUMO to increase light absorption, increasing charge mobilities to reduce recombination losses, and improving interactions with the electron donor. The first, and arguably the most well-understood acceptor to be introduced was the fullerene derivative, PCBM. ${ }^{59}$

\subsubsection{Fullerene}


After the initial discovery that PCBM could be used as an electron acceptor in OPV devices, ${ }^{20}$ fullerene derivatives have shown great successes over the years in combination with a range of donor polymers. Indeed, until the past decade, by far the most studied molecules for OPV were those based on $\mathrm{C}_{60}$ and $\mathrm{C}_{70}$.

Fullerenes are football-shaped molecules made of hexagonal and pentagonal rings and are constituted only of carbon atoms; each atom is bound to three others liberating one electron for conjugative $\pi$-bonds. In the case of $\mathrm{C}_{60}$, there are 20 hexagons and 12 pentagons. Initially it was expected that the fullerene would display complete conjugation over the whole sphere, but due to the gain in stability by the formation of alternating double and single bonds, and the spherical nature, electrons tend to circulate within each hexagonal ring, avoiding the five-membered rings. The number of carbon atoms varies from between 22 to more than a hundred but the most stable, and accessible, are $\mathrm{C}_{60}$ and $\mathrm{C}_{70}$. Generally fullerenes are prepared by burning benzene in a low-oxygen atmosphere, ${ }^{60}$ making possible multi-ton scale productions, however, complete multi-step syntheses have also been devised. ${ }^{61}$

The high electron affinity of these molecules coupled with their relatively good semiconductivity electron made fullerenes electronically interesting and promising materials. ${ }^{62} \mathrm{~A}$ downside, however, is their high level of symmetry which limits their absorption mostly to the UV region. $\mathrm{PC}_{70} \mathrm{BM}$ has been more successful than $\mathrm{PC}_{60} \mathrm{BM}$, for example, due to its better reach into visible light, making it able to participate more effectively in the formation of excitonic states, even while it has a reduced electron mobility. ${ }^{63}$
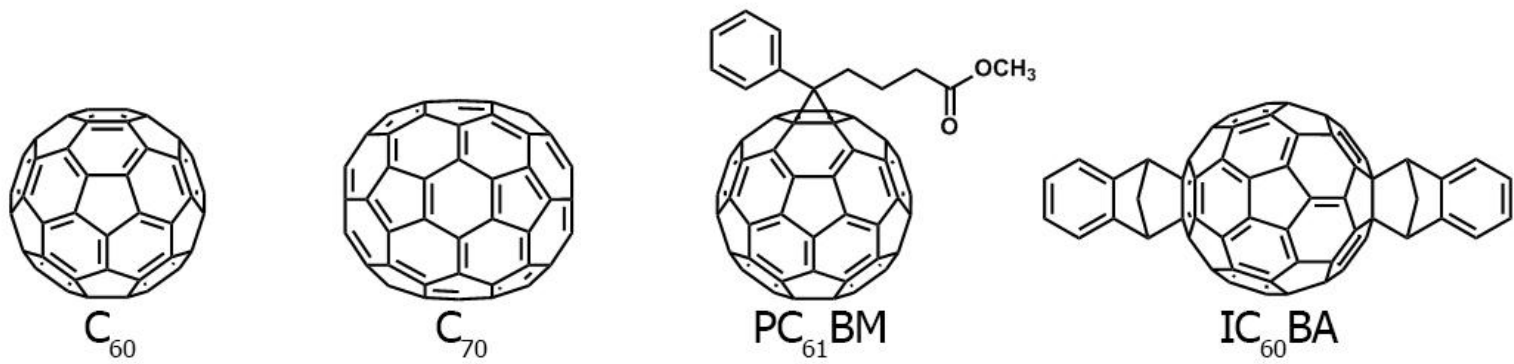

Figure 12. Structures of $\mathrm{C}_{60}, \mathrm{C}_{70}, \mathrm{PC}_{61} \mathrm{BM}$ and $\mathrm{IC}_{60} \mathrm{BA}$. 
Several works have tried to overcome the issues of improving the absorption and varying the position of the LUMO and HOMO of the molecule by changing the number and type of moieties around the fullerene core. While $\mathrm{PC}_{60} \mathrm{BM}$ was a "go to" molecule for more than two decades and remains of interest, ${ }^{37}$ others such as indene- $\mathrm{C}_{60}$-bisadduct (ICBA) (Figure 12) demonstrated that higher efficiencies could be reached. However, both it and bisPCBM, which had proved interesting due to the raised LUMO permitting improved efficiencies, their use with other polymers was limited due to poor photocurrent generation. ${ }^{64}$ An excellent review covers the range of fullerenes and its derivatives used in photovoltaics. ${ }^{65}$ However, even with these modifications, the electronic levels of fullerenes remain relatively unchangeable, making it difficult to improve the $V_{\mathrm{oc}}$. This in turn has a proportional impact on the power output of the device. The impact of the electronic levels on the $V_{\text {oc }}$ was well described making clear how order, and interfacial order, are also important in raising the output voltage. ${ }^{66}$ Increasing order, for example by removing interstitial caused by solvent molecules, and by increasing crystallinity increases the energetic gap perceived by charges moving from the device and with it the $V_{\text {oc }}$. Increasing the size of the delocalized wavefunction of the molecules can also increase the $V_{o c}$ as it reduces the energy binding the charges to their molecules, leaving greater energy available. A very recent article gives an indepth, clear and rigorous appraisal of the relationships between molecular energy levels and the $V_{\text {oc }}$ by comparing non-fullerene and fullerene-based acceptor systems. ${ }^{67}$ In any case, these challenges remain hard to resolve with fullerenes due to their inherent modular nature; as soon as a bond is made with the sphere in an attempt to extend conjugation, the actual conjugation of the sphere is lost. This means that more linear systems, that can allow for greater conjugation and wider, more delocalized wavefunctions, might be of greater interest for photovoltaic acceptors. 
While fullerenes tend to vertically organize in a device in such a way as to favor charge transfer, they also undergo excessive aggregation with time and during processing which can lead to the formation of disruptive micron-scale crystals. ${ }^{68}$ While the use of poly(fullerene) additives were found successful in arresting this process (Figure 13) and the associated 'burn-in' there was also a reduction in the initial device efficiency. ${ }^{69}$ Photooxidation was also a recurrent problem for fullerene-based OPVs, although this was effectively resolved by using nickel chelate additives. ${ }^{70}$

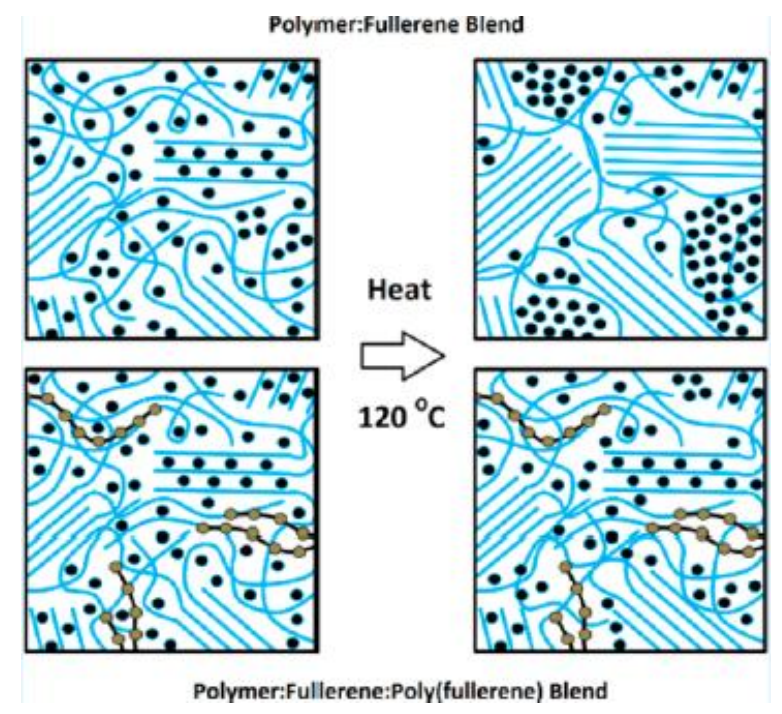

Figure 13. Cartoon representation showing how poly(fullerene)s can prevent excessive aggregation of fullerenes (in black) during processing. The blue lines are a representation of polymer donors. Reprinted with permission from reference 69. Copyright 2017 American Chemical Society.

Overall, the lack in the absorption spectra of fullerenes is a major issue and increasing the absorption of the donor to match with fullerenes has been challenging. A not inconsiderable amount of work was done to try and resolve this problem, for example that by Hudhomme and colleagues, wherein dyads combining fullerene and perylenes were explored, expanding the absorption profile of the acceptor, and permitting energy and electron transfers between the moieties. ${ }^{71,72}$ Quite spectacular dyads combining fullerenes, with for example, oligo(phenylene vinylene) were prepared and demonstrated electron transfer from the added chromophore to the $\mathrm{C}_{60}$ sphere. ${ }^{73}$ Indeed, fullerenes are certainly not out of the running as 
molecules for photovoltaics. They continue to be studied for use in multi-component activelayers where their electronic levels and absorption profiles complement the properties of other acceptors, for example, $\mathrm{PC}_{70} \mathrm{BM}$ has been useful in improving devices efficiencies and stabilities when used in a ternary blend, ${ }^{74}$ and has played a key role in tandem devices delivering $17.3 \%$ efficiencies. ${ }^{46}$ Recent work has also shown that their use as low-level additives with non-fullerene acceptors such as ITIC can improve charge-transfer in the device by aiding the formation of electron transfer pathways. ${ }^{75}$ In our own work, we have found that by using fullerene as a comonomer in alternating main-chain polymers, it is possible to raise the position of the LUMO by around $0.5 \mathrm{eV}$ with respect to PCBM by way of the type of polyaddition and comonomer used, as shown in Figure $14 .^{76-80}$ However, these variations still remain little in comparison to the so-called non-fullerene acceptors. It should be noted, that even while each measurement made to create Figure 14 was performed using the materials in the same conditions as PCBM each time, allowing some corrections for experimental set-up, the values should be treated with caution as the degrees of uncertainty, compounded when comparing materials, can be considerable when using cyclic voltammetry (CV). ${ }^{81}$ Furthermore, given that the processes in $\mathrm{CV}$ result in addition and abstraction of electrons and an ensuing variation in the structure of the molecule, the values should not be considered as indicative of energy levels, but rather in respect of ionization potentials and electron affinities. The latter, it is thought, changes the fullerene LUMO by through space interactions.

Finally, we should add that fullerene-like materials, such as carbon nano-tubes cannot be ignored. For example, carbon nano-tubes were added to improve charge transfers to the electrodes, and one could imagine that they act a bit like super-highways. This inspiring work found that it was important to orient the fibers to significantly increase efficiencies. ${ }^{82}$ 


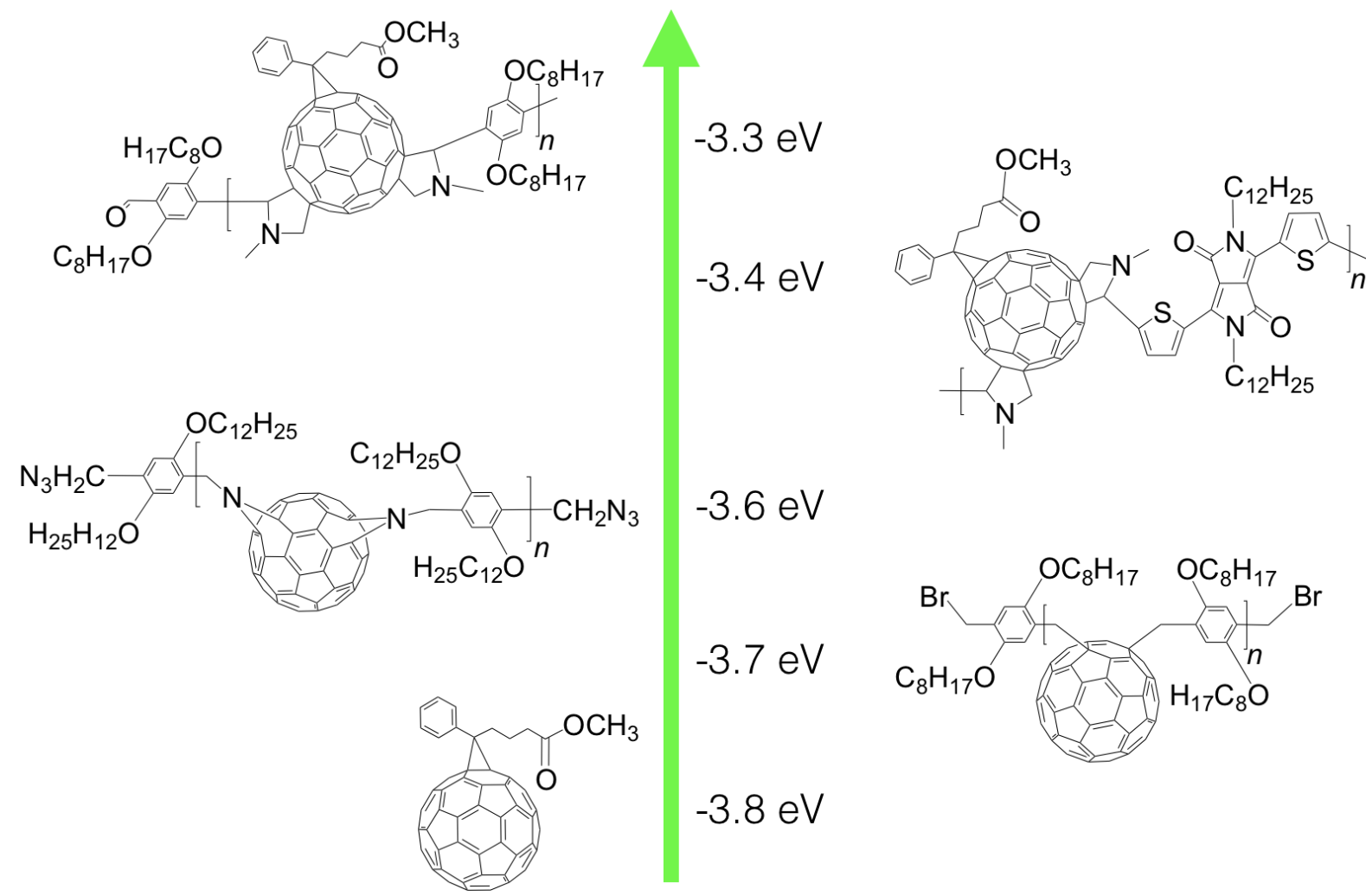

Figure 14. Exampled changes of the LUMO by incorporating fullerene into polymer mainchains. All values normalized with respect to PCBM calibrated with the ferrocene/ferrocenium $(\mathrm{Fc} / \mathrm{Fc}+)$ couple, however, please see text for a commentary on the use of cyclic voltammetry derived values.

\subsubsection{Non-fullerene acceptors}

Non-fullerene acceptors, or NFAs, have recently exploded in number and types, raining down spectacular efficiencies. This group of materials should really have a new name that doesn't simply place them with respect to fullerene as there are numerous classes, each deserving recognition. Several reviews have appeared that deal well with these materials and their design, ${ }^{11,83,84}$ not least that of Zhang et al. ${ }^{85}$ which gives an in-depth and excellent appraisal of the various chemical structures that can be encountered and explored, so here we will just point to some key leading molecules. A point common to them all, however, is their strong chromophoric capabilities which complement the absorptions of donor molecules and 
polymers. Importantly too for these systems are their ability to reduce the energy required to split excitons in bulk heterojunctions, making is possible to raise the $V_{\text {oc }}$ and the fill factor. ${ }^{86}$

One early example of interest is the helical $\mathrm{Zn}(\mathrm{WS} 3)_{2}$ shown in Figure 15 and reported by Mao et al which, when combined with P3HT, gave an efficiency of $4.1 \% .^{87}$
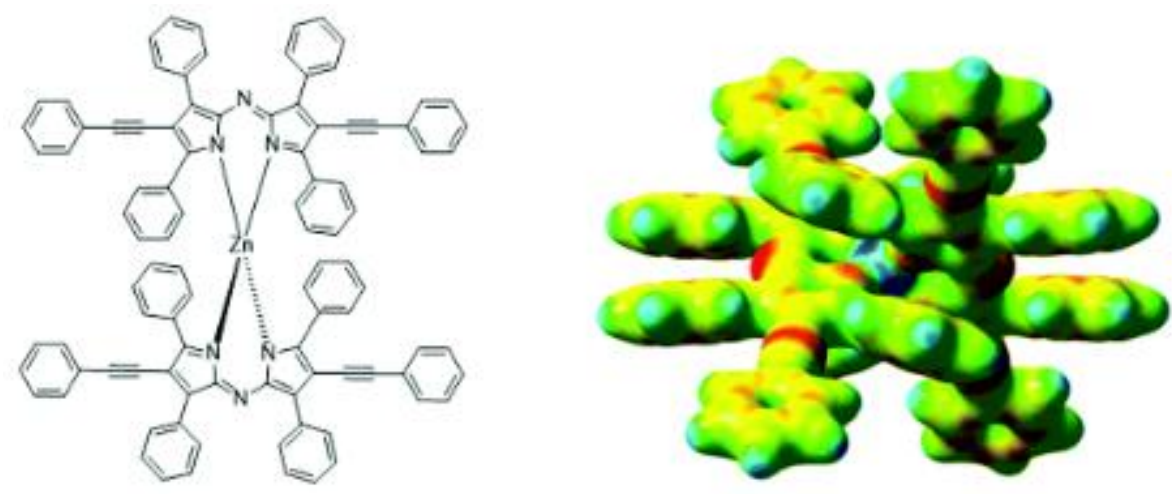

Figure 15. Chemical and 3-D structures of $\mathrm{Zn}(\mathrm{WS} 3)_{2}$, reprinted with permission from reference 87. Copyright John Wiley and Sons, 2021.

A successful strategy has come about using push-pull structures, much like those found for donors. An early example of such a molecule is FEHIDT (Figure 16) derived from indandione and giving $2.4 \%$ with P3HT in $2013 .{ }^{88}$ It is not possible to talk about ladder-type acceptors without mentioning ITIC (Figure 16), one of the most important molecular acceptors. $^{89}$ ITIC is composed of two 2-(3-oxo-2,3-dihydroinden-1-ylidene) malononitrile (INCN) acceptor groups and an indacenodithieno [3,2-b]thiophene (IT) electron-donating core. A PCE of $6.8 \%$ was first obtained when combined with PTB7-Th. ${ }^{90}$ Higher efficiencies were realized with an optimized donor ${ }^{91}$ and up to $14 \%$ was reached by adding electrondeficient fluorine substituents. ${ }^{92}$ The fluorination of ITIC, has, as mentioned above, in combination with $\mathrm{PC}_{70} \mathrm{BM}$ and F-M, with PTB7-Th and PBDB-T as donors in a tandem device delivered an extraordinary $17.3 \% .{ }^{93}$ Such efficiencies have made this molecule particularly promising, easily overtaking fullerene-based acceptors. Other work has also shown that these systems are adaptable to non-chlorinated solvents making them more 
accessible for industrial processing. For example, tertiary blends of fluorinated ITIC (ITIC4F) and new extended NFAs with acceptor-( $\pi$-conjugated)-donor-( $\pi$-conjugated $)$-acceptor structures with PM6 have delivered $11.1 \%$ efficiencies. $^{94}$
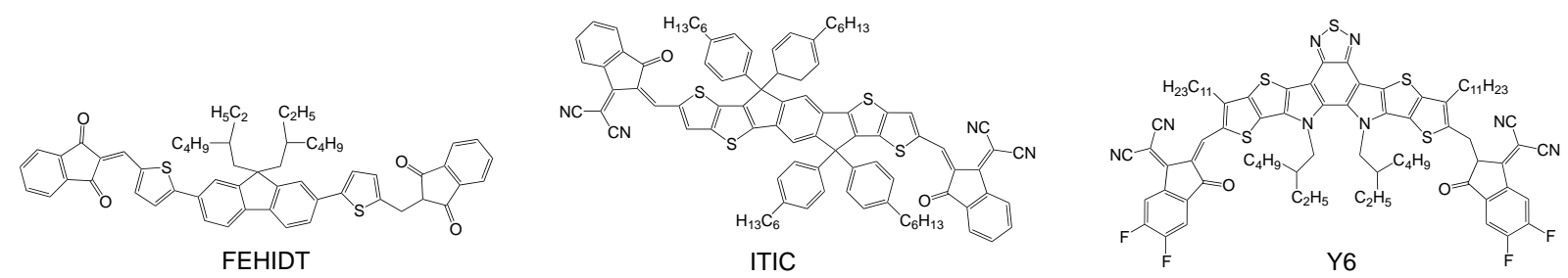

Figure 16. The chemical structures of three key NFAs.

Another recently advanced molecule is Y6, also shown in Figure 16, which when associated with PM6 brought about an efficiency greater than $16 \%$ in $2019 .{ }^{95}$ This molecule is constituted of two flat units with a 17.5 degree dihedral angle twist between them and two pairs of alkyl chains, used to increase the solubility and reduce excessive $\pi$ - $\pi$ stacking. It possesses a wide absorption spectrum and has a good thermal stability, with a high decomposition temperature of $318{ }^{\circ} \mathrm{C}$, amply enough to fit processing requirements which are generally never more than around $140{ }^{\circ} \mathrm{C} .{ }^{96}$

A particular class of molecules based on rylene diimides, which include perylene diimides are also of strong interest due to their great robustness and stability, and have been widely used in industry as dyes for paints and so on. These materials have again been well reviewed, ${ }^{85,97}$ however, it is worth pointing out that these large, flat aromatic molecules, are very interesting for their modularity and modifiability. For example, a recent class of asymmetric rylene-based benzothioxanthanes has been discovered by Blanchard and Cabanetos and coll. which are of high interest due to their facile modification. ${ }^{98,99}$ 


\subsubsection{Polymer acceptors}

Since the first independent discoveries of polymer-polymer based devices based on poly(phenylene vinylene) (PPV) electron-acceptor and electron donors by Friend and Heeger and their colleagues back in $1995,{ }^{100,101}$ this field has undergone exceptional development.

The benefits of polymers are clear: these materials are more robust, stable and malleable than their molecular cousins, and can be solution-cast or melted due to their covalently-linked and entwined structures. However, polymers are generally more complicated to synthesize than small molecules, and difficulties can arise with respect to solubility, reproducibility, and purification. Another brake to development is that polymers tend to transport positive charges, or positively charged polarons, ${ }^{102}$ much more easily than negative charges. ${ }^{30}$ Furthermore, their inherent complexity has meant that their efficiencies have lagged slightly behind those of polymer:small molecule systems, but nevertheless, there has been a steady and consistent increase over the last few years, and recent results are extremely encouraging.

Initial work centered on using electron withdrawing groups to tune the energy levels and the intermolecular interactions. A fine example of this is the aforementioned PPV modified with cyano groups, as shown in Figure 17. Later, more complex subunits were used, and Figure 17 shows some key comonomers, for benzothiadiazole (BT), bithiophene imide (BTI), perylene diimides (PDI), naphthalene-diimide (NDI), diketopyrrolopyrrole (DPP), and indacenodithiophene (IDT). ${ }^{103,104}$ From these "components", various polymers have been synthesized, characterized and tested, and Figure 18 shows some of the outstanding polymers that have come to the fore, such as poly(benzimidazole benzophenanthroline) (BBL), ${ }^{105}$ which showed $4.6 \%$ when used in bilayer devices with PPV-based donors, ${ }^{106}$ and poly[ $\left(N, N^{\prime}\right.$-bis(2octyldodecyl)-naphthalene-1,4,5,8-bis(dicarboximide)-2,6-diyl)-alt-5,5'-(2,2'-bithiophene)] (N2200) which gave a particularly strong impetus to the field. N2200, originally prepared for 
transistors, was found to have an exceptional electron mobility (up to $0.85 \mathrm{~cm}^{2} \mathrm{~V}^{-1} \mathrm{~s}^{-1}$ ), ${ }^{107}$ but was rapidly explored for OPV. For example, it was found that the all-polymer device, combining N2200 with the polymer donor J51 delivered an efficiency of $8.27 \% .^{108}$ The NDI core of the N2200 polymer, is very much still considered an important group, and the exploration of minor structural modifications has led to continued improvements in efficiencies. ${ }^{109}$ Another route that is being explored is the use of N2200 as an additive to a polymer donor:small molecule acceptor system, making feasible a $13 \%$ efficiency by improving the morphology. ${ }^{110}$ Another system of interest is that based on the electronaccepting building block called isoindigo. This easily prepared material has been exploited as an acceptor both in small molecules and in polymers. ${ }^{111,112}$

Other more recently developed polymers which are opening roads to new high efficiencies include a low band-gap polymer L14 which is based on the combined acceptoracceptor units BTI and a large fused-aromatic group based around the BT group has been particularly successful, with an efficiency of $14.3 \%$ recorded when used with the donor polymer PM6. ${ }^{113}$ Another recent contribution has shown that polymer-polymer cells can go through the $15 \%$ barrier. A new series of polymers based around the benzotriazole-core fused system (i.e., like BT but with a nitrogen replacing the sulfur atom) were developed with PZT$\gamma$ (Figure 18) leading the pack and giving an efficiency of $15.8 \% .^{114}$

It should be noted that these polymers were particularly well reviewed. ${ }^{115}$ Finally it should also be mentioned that ternary systems, that is combining, for example two donor polymers and an acceptor, can reduce energy losses. Ma et al. showed that by combining PF2 and J71 donor polymers with the acceptor Y6, they were able to raise the efficiency from, respectively $10.26 \%$ and $9.56 \%$ for the binary systems to $12.12 \%$ for the ternary device. ${ }^{116}$ 
<smiles>CC(C)=Cc1cc(O)c(C)cc1O</smiles>

CV-PPV<smiles>Cc1ccc(C)c2nsnc12</smiles>

BT<smiles>[Y9]c1csc2c1c(=O)n(P)c(=O)c1c(C)csc12</smiles>

BTI<smiles>[R]N1C(=O)c2ccc3c4cc(C(C)(C)C)c5c6c(ccc(c7cc(C)c(c2c73)C1=O)c64)C(=O)N([R])C5=O</smiles>

PDI<smiles>[Y6]c1cc2c3c(c(C)cc4c3c1C(=O)N([R7])C4=O)C(=O)N([Y9])C(=O)C2=O</smiles><smiles>CCn1c(=O)c2c(=O)n(P)c(=O)c=2c1=O</smiles><smiles>[R]N1B(F)c2cc(C)cc3c2c2c(cc(C(C)(C)C)cc2n3[R])B1F</smiles><smiles>[R]C1([R])c2cc3c(cc2-c2sc(C)cc21)C([R])([R])c1cc(C(C)(C)C)sc1-3</smiles>

IDT

Figure 17. Chemical structures of key comonomers used in polymer-based electron acceptors, showing their commonly used points of polymerization. Adapted from reference 116.

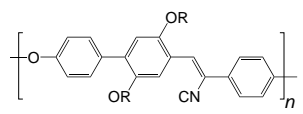

CN-ether-PPV
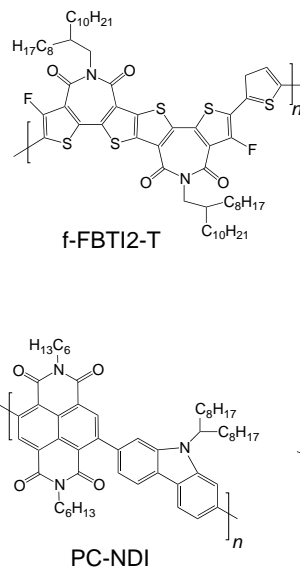

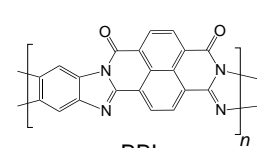

BBL

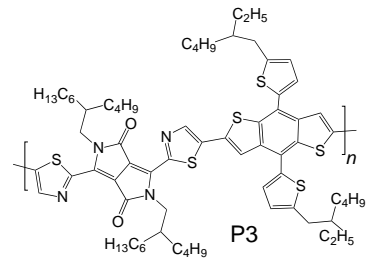

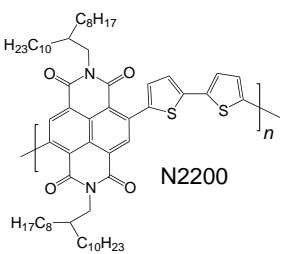

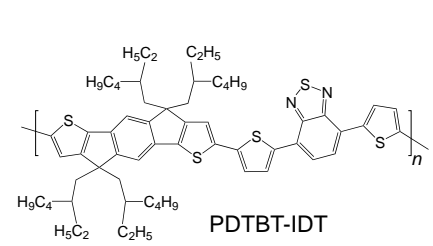

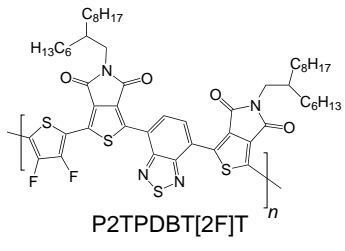

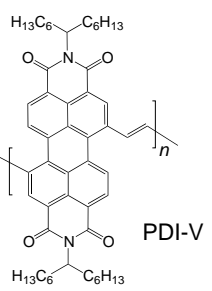

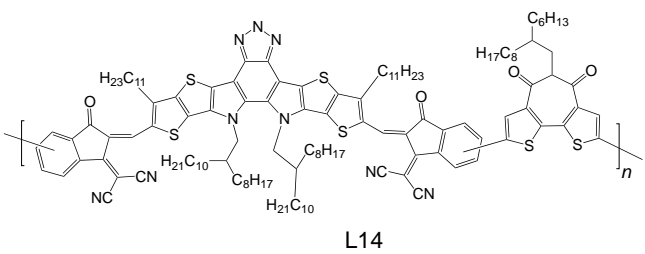

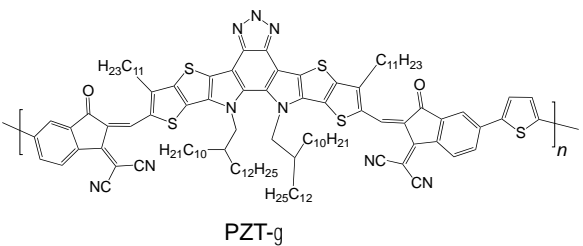

Figure 18. Some key polymer acceptors.

\section{3 (Macro)molecular modifications}

The syntheses of polymers for OPVs is outside the scope of this review, and the reader is pointed to the works by Marzano et al. on industrially relevant syntheses, ${ }^{118}$ Yokozawa and 
Ohta for an overview of polymer syntheses for conjugated polymers, ${ }^{119}$ Okamoto and Luscombe on controlled polymerizations, ${ }^{120}$ and also to the more recent and exciting development of the more environmentally benign direct arylation polymerizations. ${ }^{121}$

Here we look more to the fine modification of single atoms around an acceptor or donor molecule or polymer which can give rise to less obvious but nevertheless incredible changes in the properties of the materials. Not only can these small structural changes impact on the crystallinity, and hence charge-transfer properties of the materials, but also their chromophoric nature and electronic properties. This high degree of variability, a canvas for chemists to unleash their creativity on some might say, is the very reason by which organic photovoltaics can deliver exceptional materials with tailored properties. This exceptional degree of variability can also be a hindrance in that so many possibilities need to be explored. In this sense modelling is exceptionally important in being able to pinpoint key variations, as discussed towards the end of this work, along with methodologies that can quickly identify efficient pairs of donors and acceptors materials. ${ }^{122}$

Here we give some examples of how small variations can impact heavily on material properties. For example, in their work, Liu et al. ${ }^{123}$ explored the molecules shown in Figure 19. With just one minor modification in the position alkyl chains on the core aromatic group, they found not only a sharp change in $\pi$ - $\pi$-stacking of the molecules but also a change in electronic quality. BTCN-O, in contrast to BTCN-M, was found to give strong packing, and this allowed it to behave as a donor with the electron acceptor $\mathrm{PC}_{71} \mathrm{BM}$. However, BTCN-M, was better placed to act as an acceptor with the donor polymer, PBDB-T. This work clearly demonstrated how packing impacts on the electronic qualities of the materials. 

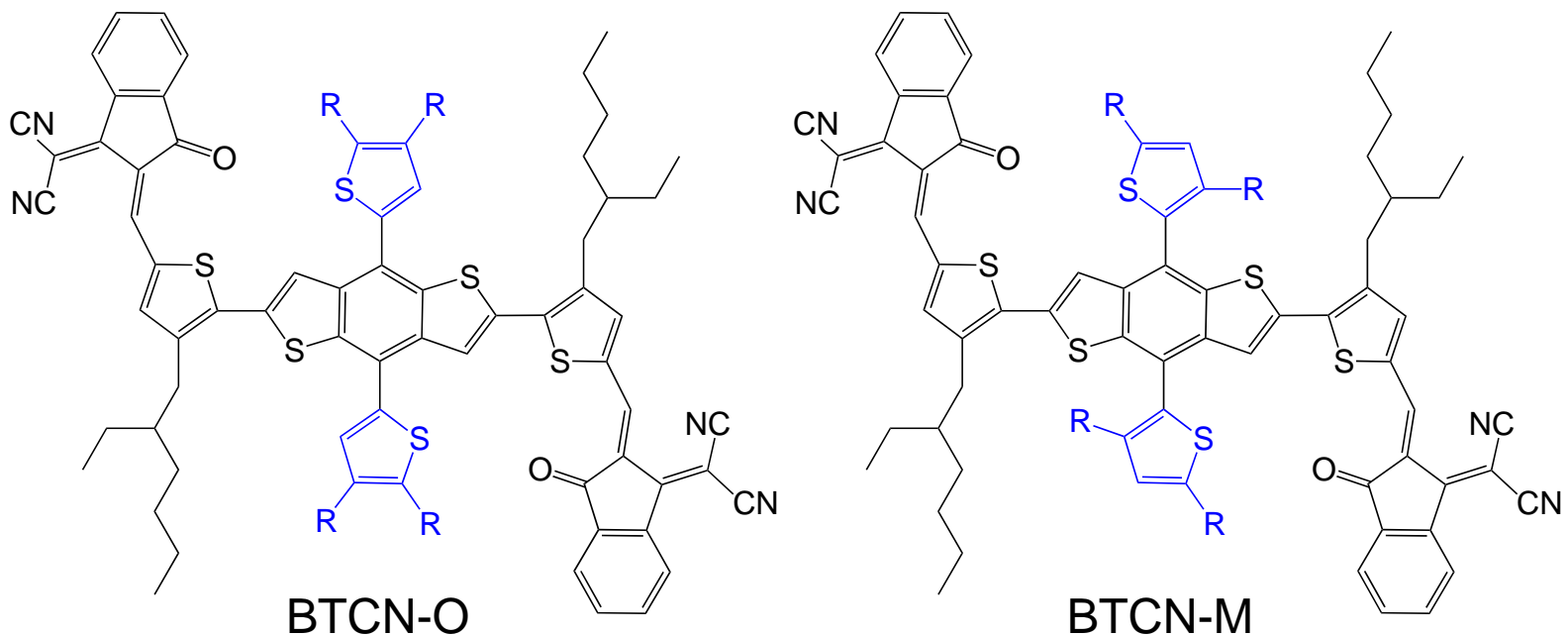

Figure 19. Molecular structure of $B T C N-O$ and $B T C N-M$ in which $\mathrm{R}=\mathrm{n}$-octyl, adapted from reference 123.

Less startling, but certainly important, is the well-understood impact of alkyl sidechains on behavior. The presence of long alkyl chains attached to rigid backbones, increases the steric hindrance effects, pushing the molecules further from each other and allowing a more effective interaction with the solvents. In this sense, the solubility and crystallinity of the materials can be tuned according to the length of side-chains. Generally, compounds with longer side-chains exhibit higher solubilities, but poorer crystallinities and ordered morphologies. Furthermore, hexyl and dodecyl side-chains lend greater crystallinity to polymers as they tend to allow interdigitation of side-chains. P3HT is a well-known example of this effect, showing considerably better properties than its butylated or octylated cousins. Polymer branching can also highly impact on crystallinity. A classic study was that by Savikhin et al. which demonstrated how side-chains not only affect the assembly and packing of chains, but also the domain formations between donor polymer and the acceptor. ${ }^{124}$ Even though the side-chains do not play a direct role in the light absorption, they can be used to tune the energy level of compounds as they can induce a twisting in the molecules. ${ }^{33}$ In this context, the steric hindrance induced by cumbersome side-chains can twist the backbone of 
the compounds leading to significant changes on their $\pi$-systems to modify the relative position of the frontier molecular orbitals.

Moreover, some studies have been conducted to investigate how the choice of side groups can affect the performance of branches as effective spacers. Jiang et al. ${ }^{125}$ showed the effect of the branching on the solubility, electronic and morphological properties of Y6 (Figure 20). They also proved the effect of the position of the side-chains by swapping them with the n-alkyl chains placed farther from core of the molecule. This work gained an exceptional efficiency of more than $16 \%$.

Of increasing interest is using side-chains to modify the solution properties of the polymers. In a forward looking study, Chen et al. studied the use of oligo(ethylene oxide) side-chains so as to solubilize the polymers in environmentally friendly solvents, to which end they arrived at highly respectable efficiencies of more than $7 \%$ with the non-fullerene acceptor IT-M. ${ }^{126}$ 


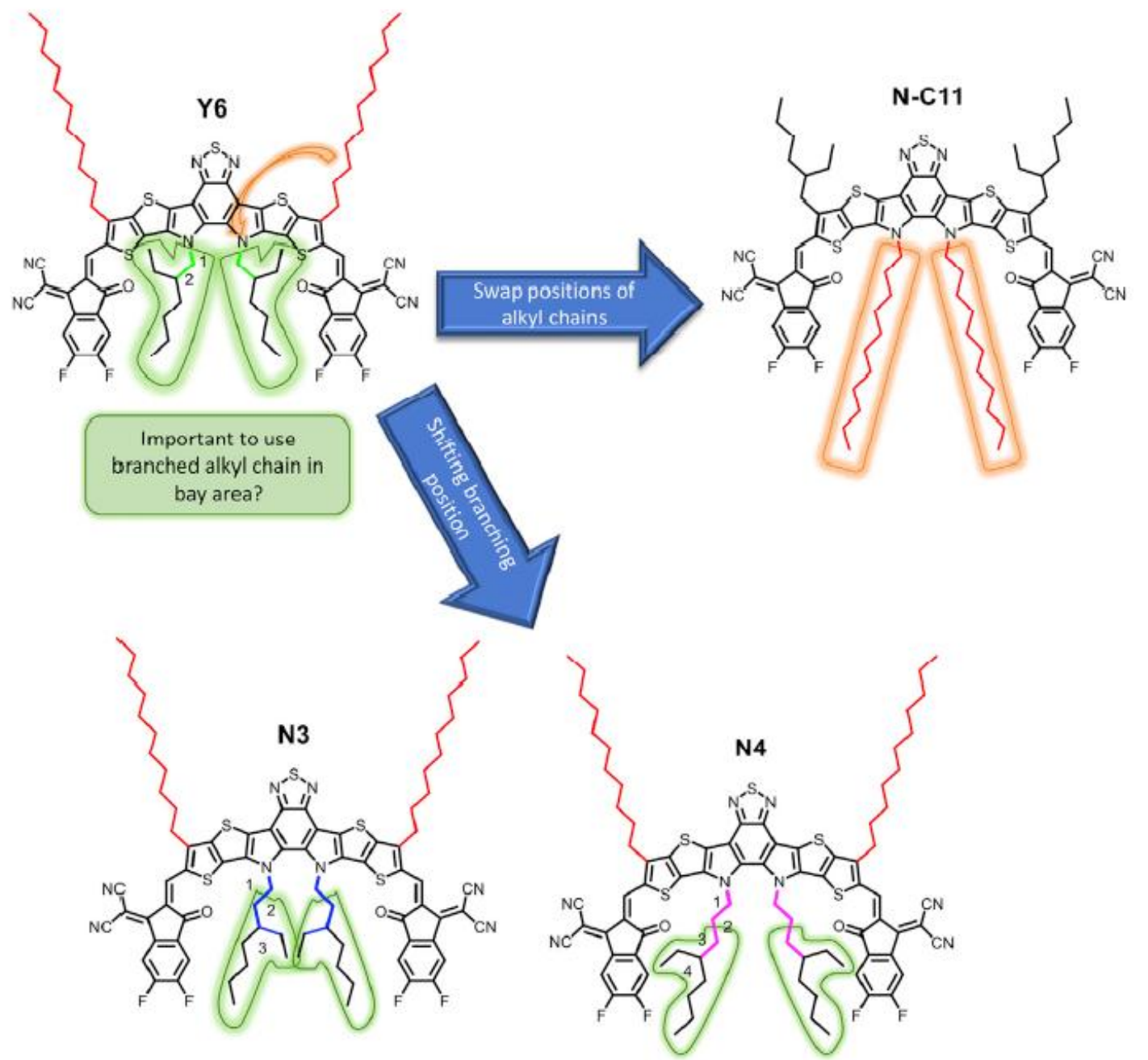

Figure 20. Molecular structure of the different molecules studied by Jiang et al. showing the effect of the side chain engineering on Y6. Reprinted with permission from reference 125. Copyright Elsevier 2019.

Another parameter that is crucial for OPVs efficiency is the halogenation of the system. ${ }^{127-130}$ The use of halogens (in particular fluorine), can help finely tune the molecular orbitals to increase the $V_{\mathrm{OC}}$ values. ${ }^{131}$ It also enhances intra- and intermolecular interactions due to their electron withdrawing properties and electrostatic role, increasing the charge carrier mobilities and improving the PCE. Bai et al. ${ }^{132}$ studied the same molecule with different number of halogenate substitutions and showed that the molecular geometries of the molecules are not affected by the halogen atoms, but they greatly affect the position of the 
frontier molecular orbitals (HOMO and LUMO levels), which is determining for matching materials. They also showed different exciton dissociation rates depending on the quantity of substitutions (with a maximum at 8 fluorine atoms in their molecule) with significantly reduced charge recombinations. Unexpectedly, the random placing of fluorine atoms along a p-type polymer made of alternating isoindigo and carbazole moieties made possible their good solubilization in a non-chlorinated solvent and therefore of relevance to industry, $o$ xylene, made possible efficiencies of $7.5 \% .^{133}$

\section{Morphology and Block Copolymers}

The first OPVs had active-layers made of two stacked films of the donor and acceptor, as shown in Figure 21a. However, as discussed above, the efficient conversion of an excitonic state into a pair of charges requires that the exciton is formed close enough to a D-A. Excitons can diffuse through active-layers to reach an interface, ${ }^{134,135}$ however, the typical diffusion lengths are around $10 \mathrm{~nm},{ }^{136}$ which means that any exciton created at distances further away can be lost, resulting in a reduced efficiency.

Unfortunately, for a film to efficiently absorb all the light it needs to be relatively thick, at least several hundreds of nanometers. Furthermore, industrial roll-to-roll processes require thick films to reduce the number of pinholes which can lead to short circuits, again meaning that thick films are, within cost constraints, preferred.

As mentioned earlier, a real jump in efficiency was made when $\mathrm{Yu}$ et al $^{23}{ }^{23}$ discovered the BHJ shown in Figure 21b. In these devices, the D and A materials are blended, leading to the formation of numerous interfaces throughout the bulk. Fortuitously, there can be mixed zones in which donor and acceptor closely mingle which can improve efficiency further by making available additional sites for charge formation. ${ }^{137}$ Treatments such as annealing, ${ }^{138}$ the use of additives ${ }^{139}$ and nucleating agents to facilitate control over phase separation, ${ }^{140}$ 
modulation of growth rates ${ }^{141}$ can further improve the morphology by creating, for example, more crystalline zones which can enhance charge transfer away from interfaces to the electrodes. $^{142}$

Given the limited solubility between the employed compounds, they form an interpenetrating network with nanometric domains. The number of interfaces is increased and due to this nanoscale, the number of exciton losses is largely reduced. Moreover, it is possible to tune the size of the domains during the production process, by to obtain the efficient structures.

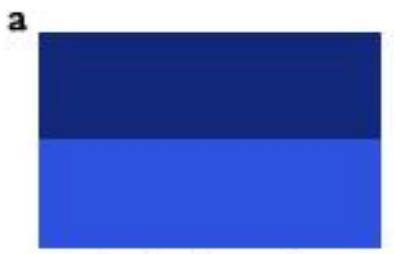

single junction

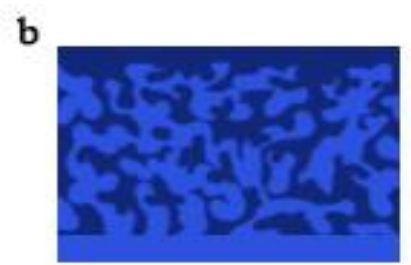

BHJ

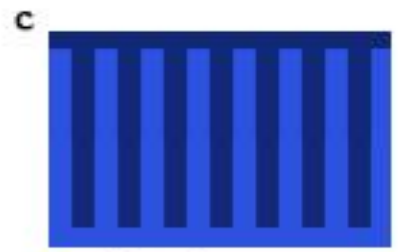

ideal structure

Figure 21. Different morphologies of an OPV active-layer: a) single junction, b) bulk heterojunction (BHJ) and c) a postulated ideal morphology.

These characteristics have made the BHJ the most successful morphology for OPVs. But the BHJ still has issues, as the disorder in the bulk generates some isolated domains that can trap free charge carriers and prevent them from reaching the electrodes. ${ }^{143}$ Also, the longer and disordered (spatially and energetically) paths increase the chances for charge recombination. Simply put, charge percolation directly to the electrodes is very important, and some paths can be dead-ends because of the randomness of the morphology. The charge carrier losses could be reduced in more organized bulk heterojunctions. ${ }^{144}$

It has often been stated that the ideal morphology should be based on lamellar structures (Figure 21c) which would transfer the charge directly to the electrodes. ${ }^{25}$ The use of block copolymers (BCP) have been proposed as a route to obtain such a morphology, ${ }^{145-147}$ 
and an important step in demonstrating their use was performed by Lindner et al. who showed that like-for-like block copolymers outperformed a BHJ of their constituent blocks. ${ }^{148}$

The principles, operation and development of block copolymers has been thoroughly reviewed, ${ }^{7,149-153}$ so we will just give a simple overview here. BCPs are polymeric structures composed of two blocks with distinctly different chemical structures, as shown in Figure 22. If the two blocks are cast from solution, and the blocks have different enough interaction parameters and are long enough, then each block will separate into domains while still remaining tied to the other block. This effect can be further enhanced by the crystallization of each block with its own type. Interestingly, various structures can be formed by changing the lengths of the polymers and their degrees of interaction, such that their phase diagrams can include the lamellar structures shown in Figure 22, but also cylinders and gyroids, which would also be interesting as they have high interfacial surfaces and direct percolation routes to the electrodes for charges. Given this, it would seem straight forward to tie an acceptor block and a donor block together depending on different parameters and then bring them together by solid-state self-assembly to give the structures shown in Figure 22. However, BCPs have lagged far behind most BHJs, and indeed most polymer:polymer systems because of the complexity of their synthesis and the staggering number of variations that can be incorporated into their structures, making it harder to find the ideal structures. This does not mean that this line of research should not be followed... far from it! These materials offer much greater strength and mechanical robustness by way of their interconnected domains, and are expected to ease processing as they contain all that is required for the active-layer in one macromolecule. All this without mentioning that they are also expected to deliver higher efficiencies, not only because donor and acceptor are aligned together to ensure exciton transformation to charges, but because the charges can be shuttled directly to the electrodes. Fundamental studies have also shown that block copolymers should give much higher 
efficiencies than blends of their component blocks alone. ${ }^{146}$ Furthermore, the variables can be pinned down to: changing the lengths and dispersities of the different blocks; the type and size of connecting and chain-end groups; and the multiplicity of the blocks (diblock, triblock or multiblock). That these materials remain, for many, an ideal to strain for is given empirical evidence by a track-record which demonstrates their ever-increasing efficiencies. Earlier works with highly creative studies, using either pendent chromophores on electronically inert polymers such as the aforementioned paper by Lindner et al., or copolymers that combined conjugated blocks of $\mathrm{PPV}^{154}$ or P3HT with vinylic polymers carrying pendent perylenes ${ }^{155,156}$ or fullerenes ${ }^{157}$ gave great impetus to the field. Belying the complexities of designing and synthesizing these systems, early works demonstrated quite low efficiencies, less than a per cent or so. However, by careful control of the morphology, for example by using block copolymers as templates, ${ }^{158}$ or by careful synthesis of conjugated P3HT carrying fullerenes, ${ }^{159}$ $1.7 \%$ was achieved in both cases. In our own work, a block copolymer made of a main-chain poly(fullerene) with P3HT managed $2.8 \%$ in a device. ${ }^{160}$ A slight increase was made by Guo et al., reaching $3.1 \%$ and an exceptional $V_{\text {oc }}$ of $1.23 \mathrm{~V}$ for a hero cell using poly(3hexylthiophene)-block-poly((9,9-dioctylfluorene)-2,7-diyl-alt-[4,7-bis(thiophen-5-yl)-2,1,3benzothiadiazole]-2',2"-diyl) (P3HT- $b$-PFTBT). ${ }^{161}$ Later, an all conjugated P3HT-PTB7-TF system was able to deliver $3.6 \%$, this with a low processing temperature of $60{ }^{\circ} \mathrm{C} .{ }^{162} \mathrm{~A}$ more recent, and outstanding result was delivered by Yu et al. who managed to show $6.25 \%$ for a selenophene-based block copolymer carrying pendent perylenes. ${ }^{163}$

Considerable advances have been made by using BCPs as additives to BHJs, most likely because they enforce and stabilize regular domain formation. Again in our own work, we found that our P3HT-poly(fullerene) copolymer boosted efficiency from 3.6 to $4.2 \%$ and maintained long-term stability. ${ }^{160}$ Considerable advances have been made since then, not least the work by Su et al. which demonstrated a P3HT analogue, PDCBT when used as a block 
copolymers with polystyrene, they could increase the efficiency for a device from 6.21 to $8.04 \%$ for PDCBT blends with the NFA IT-M. ${ }^{164}$

(a)

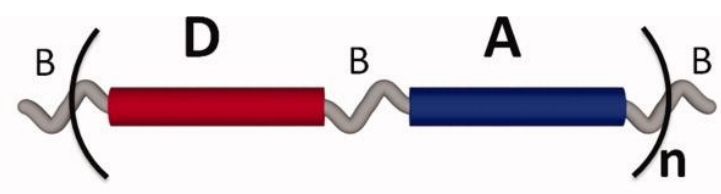

(b)

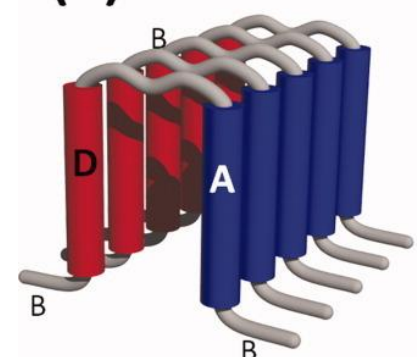

(c)

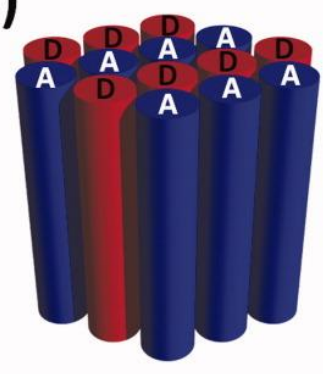

(d)

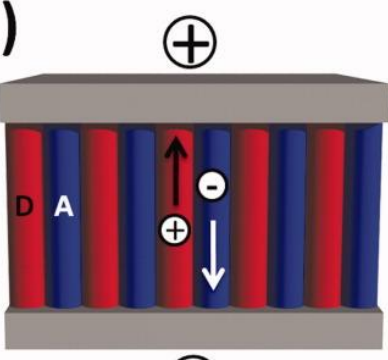

$\Theta$

Figure 22. How block copolymers might self-assemble to give rise to an ordered system to efficiently transfer charges to the electrodes. Reprinted with permission from reference 7 . Copyright John Wiley and Sons.

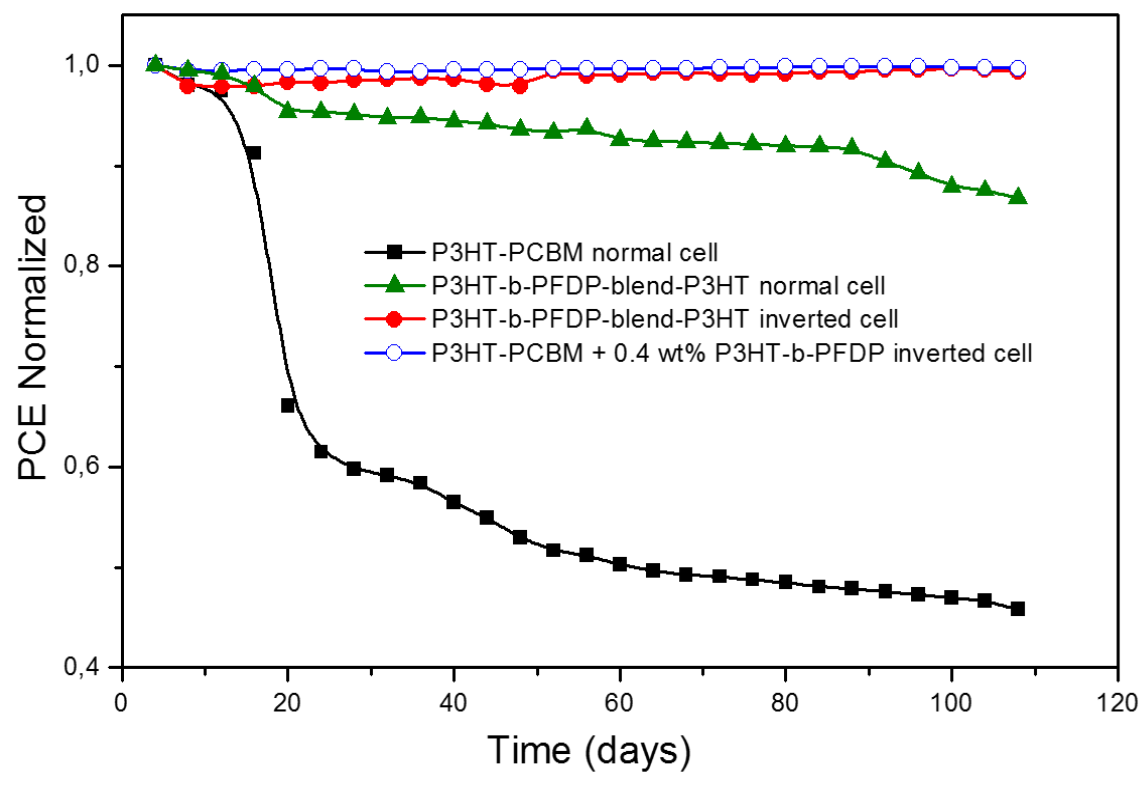

Figure 23. Normalized PCE over time for four different cells. In black the PCE of a P3HTPCBM normal cell and in green and red same active materials but as a BCP in a normal and inverted cell, respectively and finally in blue, the same cell as in black but with BCP as an additive. Reproduced from reference 160 with permission from the Royal Society of Chemistry. 


\section{Molecular modeling of D-A interfaces and interactions}

As evidenced in this review, the performance of OPVs is strongly governed by donoracceptor (D-A) interfaces. However, at nanoscopic scales it is very difficult to access experimental data for D-A interactions. In this sense, molecular modeling techniques can be considered important tools, allowing the identification of specific interactions and the investigation of basic mechanisms.

Historically, the modeling of OPVs has been conducted at varied levels, focusing on the distinct processes that take place in these devices, and on the variety of materials and architectures employed throughout the years. ${ }^{165}$ In fact, most of these theoretical studies studied the intrinsic properties of the materials that make up the devices (e.g. donors, acceptors and electrodes) and/or on their interactions/interfaces, once these two factors are supposed to modulate, in some degree, the variety of, generally complex, processes associated with the functioning of OPVs. ${ }^{166,167}$

For this purpose, different approaches and levels of theory have been employed at distinct scales, which can be generically divided into those based on: i) quantum mechanics $(\mathrm{QM}) ;^{168-171}$ ii) (semi) classical molecular mechanics (MM) and/or molecular dynamics (MD); 172,173 iii) microscopic phenomenological approaches (e.g. drift-diffusion equations, DDE) ${ }^{174,175}$ kinetic Monte Carlo (KMC), ${ }^{176-178}$ master equations; ${ }^{179}$ and iv) others (e.g. based on equivalent circuits. ${ }^{180}$ Very recently, additional approaches involving machine learning have also attracted great attention. Most of these methods, however, uses optoelectronic and morphological data coming from $\mathrm{QM}$ and $\mathrm{MM} / \mathrm{MD}$ to feed training sets in order to establish significant structure-property relationships. ${ }^{181,182,184}$

Indeed, a number of $\mathrm{QM}$ and $\mathrm{MD}$ based studies have been conducted to evaluate morphological and optoelectronic/electrical properties of OPVs. ${ }^{19,181,184-189}$ In QM treatments, 
the electronic structure of the systems are described by considering electron-electron, electron-nucleus and nucleus-nucleus interactions. In this context, approaches based on the Hartree-Fock (HF) method and on the density functional theory (DFT) (as well as their latter developments and approximations) are commonly employed in the study of multi-electronic systems at reasonable computational costs. ${ }^{168-170}$ Once QM approaches allow an appropriate description of the electronic structure of the systems, they define interesting tools for the design and proposition of new compounds, mainly focused on gap engineering (modulated by the choice of distinct side groups and/or building blocks), optical properties, and frontier levels alignments (e.g. HOMO, LUMO, electrode work functions, and their relative differences, i.e., $\Delta E_{\mathrm{HD}-\mathrm{HA}}, \Delta E_{\mathrm{LD}-\mathrm{LA}}, \Delta E_{\mathrm{LA}-\mathrm{HD}}$, and injection/collection barriers) which can be directly predict from isolated structures (or medium size complexes) and are supposed to play a relevant role in the dynamics of charge carriers and excitons in OPVs. ${ }^{190-196}$ In addition, QM methods are generally used to describe/tune specific geometrical parameters, ${ }^{197}$ stability and degradation process, ${ }^{198,199}$ predictions for ideal donor: acceptor pairs to improve organic photovoltaic lifetimes and efficiencies ${ }^{200,201}$ chemical reactivity and electrical charges of force fields used in MM/MD simulations. ${ }^{202,203}$

In $\mathrm{MM}$ and $\mathrm{MD}$ simulations, the interactions between molecules and atoms are described by a set of classic parameters, called force fields (commonly parameterized by QMbased calculations). Average values of observables, morphological features and thermodynamic data are then estimated by solving the Newton's equations of motion, considering an specific ensemble and time of simulation (for MD). ${ }^{172,173}$ In general, once the electrons are not explicitly considered in these approaches, it is not possible to describe chemical reactions or charge transfer processes. However relevant details associated with the formation of interfaces and disposition of hopping centers (conjugated portions of the D and A materials) that are quite compatible with real systems can be obtained from MD 
simulations, which can improve the description of charge transport via phenomenological approaches $^{204,205}$ and identify relevant intermolecular interactions for QM calculations with reduced computational costs..$^{206-208}$ In addition MD simulations are widely used to investigate stacking properties, radial pair distribution of atoms/molecules and other morphological features.

Besides the molecular modeling techniques (QM and MM/MD), different theoretical approaches have been used to simulate the charge transport in organic devices from the microscopic point of view. ${ }^{209,210}$ In these systems, the high degree of spatial and energetic disorder of the electronic levels leads to the formation of spatially localized states throughout the material, that limit the dominance of band-like electronic transport; so, the charge transport is commonly dominated by thermally activated charge hopping processes (from occupied to unoccupied sites), which are guided by the energetic and spatial configuration of the system and external stimuli, as electric fields and temperature. ${ }^{210,211}$ For this reason, the charge transport in these devices is generally simulated by considering a network of threedimensional hopping sites (which correspond to conjugated molecules or planar sub-segments of polymers) in which excitons and free charges are let to evolve. ${ }^{212-214}$ All these microscopic approaches, however, are clearly dependent on the spatial and energetic distribution of electronic states, as well as, intrinsic features of the compounds (charges mobilities, internal reorganization energies, charge transfer integrals, etc.) and their interactions (e.g. interfaces, stacking, morphology, polarization, etc.) which can be predicted by molecular modeling techniques (MD and/or QM), giving place to multi-scale OPV simulations. ${ }^{211,215,216}$

In particular, in the context of OPV simulation, an intermediate and unexplored approach for conducting MD simulations with some contribution of the electronic features is the use of the so-called reactive force fields. ${ }^{217}$ Among the available approximations, the ReaxFF is a very interesting alternative, being successfully used in the description of varied 
systems: including hydrocarbons, ${ }^{218}$ fullerenes, ${ }^{219}$ graphenes, ${ }^{220,221}$ oxides, ${ }^{222,224}$ degradation of polymers $^{224}$ and interaction of gases with surfaces ${ }^{220,225}$ and polymers. ${ }^{226,227}$ These force fields are defined according to the bond orders of a pair of atoms (estimated via DFT calculations), allowing to reproduce the bond breakage/formation during the simulations. ${ }^{222,228}$ In this sense, very compatible results are generally obtained in relation to QM approaches. In addition, long range (Coulombic and van der Waals) interactions are also considered, allowing a good description of unbound states and steric interactions.

Once ReaxFF depends on a correct parameterization of the system under study, one of the initial issue is the appropriate adjustment of the atomic parameters. Indeed, despite the vast majority of atoms commonly present in OPVs have already been parameterized $(\mathrm{C}, \mathrm{H}, \mathrm{O}$, $\mathrm{N}, \mathrm{S}, \mathrm{Cl}, \mathrm{F}$, etc), additional parameterizations can also be conducted via DFT calculations. ${ }^{218,229}$

Although the computational cost of a ReaxFF/MD approach is relatively higher than simulations with non-reactive force fields, they are significantly more accessible than QM approaches, allowing the investigation of relatively large systems. ${ }^{219,230}$ Due to its parameterization, it is also possible to distinguish physisorption and chemisorption phenomena, however, given the absence of electrons it cannot describe charge transfer processes.

In this sense, to access details on the optoelectronic and morphological features of the compounds, QM and MD studies have been conducted in conjunction. ${ }^{181,187,188,231}$ In particular recent studies have suggested that the combination of electronic descriptors obtained via DFT and trajectory data coming from MD/ReaxFF could allow the identification of relevant adsorption centers of polymers, ${ }^{226,227}$ which could be relevant in the study of D-D, D-A and A-A interactions in OPVs. To better illustrate it, here we present a preliminary analysis of the local reactivity of the PM6:Y6 system and results coming from MD/ReaxFF simulation 
(considering decamers of PM6). This system has been chosen given its exceptional development over the last few years. ${ }^{232}$

The local reactivities of the compounds are presented in Figure 24. These colored maps of the Condensed-to-atoms Fukui indexes (CAFI) ${ }^{233}$ and molecular electrostatic potential (MEP) $)^{234}$ describe the tendency of soft-soft and hard-hard interactions, respectively. In general, soft-soft interactions take place when the molecules interact via their frontier molecular orbitals, which can lead to charge transfer and chemical reactions, while hard-hard interactions are associated with electrostatic effects with little deformation of the electronic orbitals. ${ }^{235}$ CAFI are estimated from finite differences of the electronic populations after the insertion and removal of electrons to/from the systems, ${ }^{236,237}$ generally, these indexes allow the identification of which molecular sites are prone to interact with nucleophilic $\left(f^{+}\right)$, electrophilic $\left(f^{-}\right)$and radicalar $\left(f^{0}\right)$ external agents. ${ }^{238,239}$ MEP is self-explanatory and it is estimated from atomic charges. ${ }^{234}$ All the calculations (geometry optimization and properties) were conducted in the framework of DFT by using the hybrid B3LYP functional ${ }^{240-243}$ and D3 version of Grimme dispersion with Becke-Johnson damping (GD3BJ), ${ }^{244} 6-31 \mathrm{G}(\mathrm{d})$ basis set was employed on all the atoms. Hirshfeld's partition charge method was used to estimate the CAFI to avoid negative values. ${ }^{182,245}$ In Figure 24, blue and red colors indicate, respectively, inert (or positively charged) and reactive (or negatively charged) sites from CAFI (MEP) analysis. The other colors indicate regions with intermediate reactivities (or charge concentrations) following a RGB scale. Each molecule has its own color scale. 


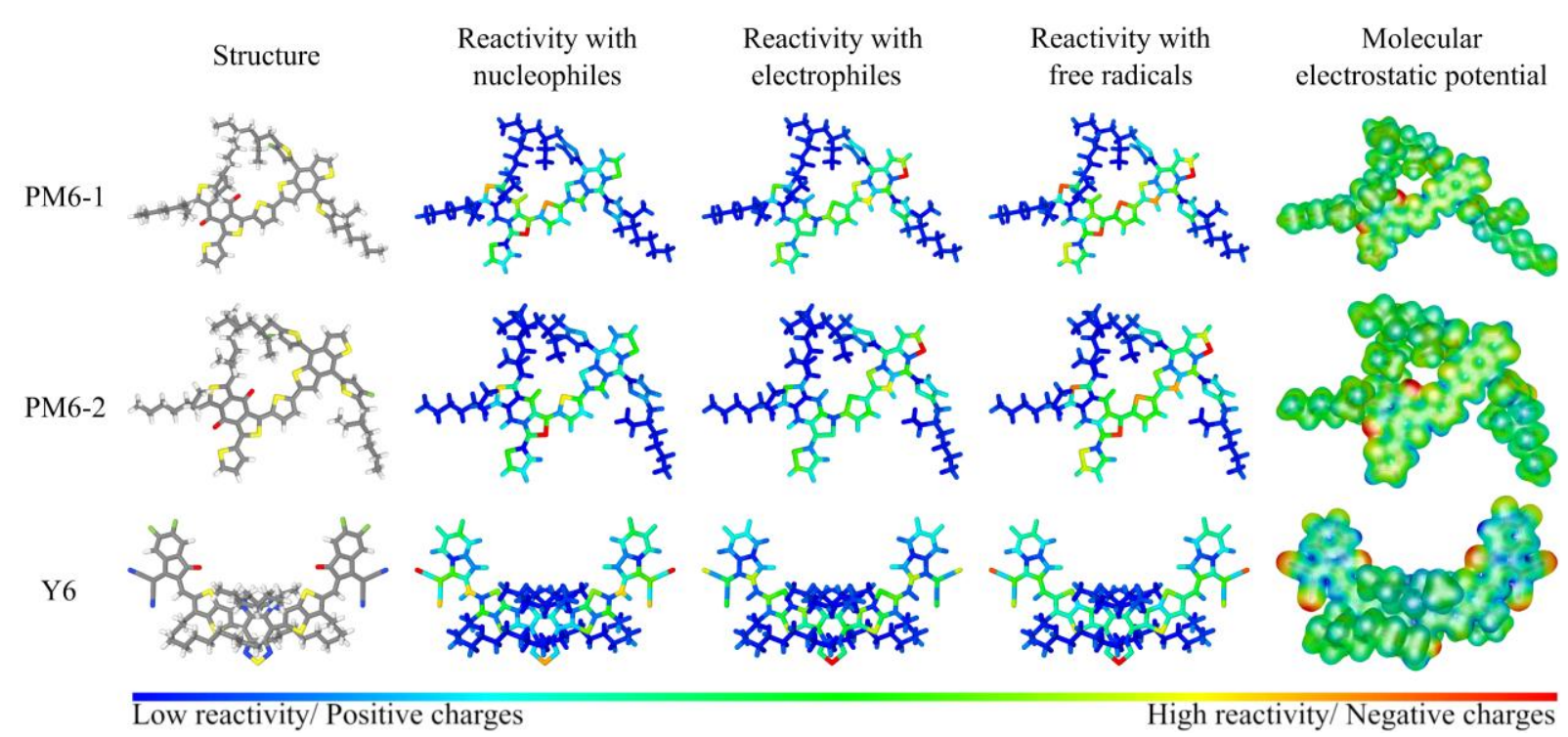

Figure 24. Structures, CAFI and MEP maps of two distinct conformations of PM6 monomer (PM6-1 and PM6-2) and Y6.

In relation to PM6, these simple descriptors can indicate how the polymer chains could interact, and what kind of relative molecular alignments could improve the inter-chain charge transfer and hole transport in the donor domains. In general it is desirable an effective interaction between nucleophilic and electrophilic sites of the molecule (red regions of $f^{+}$and $f^{-}$in Fig. 24), which are highlighted in Figure 25. In relation to Y6 it is possible to note that the charge transfer between PM6-Y6 (i.e., exciton dissociation) and Y6-Y6 (electron transport) is mediated by the central sulfur atom and $\mathrm{CN}$ side groups, with can explain the good performance of this NFA, since these sites are more exposed to the environment then the central core. In particular, the interaction of these groups with the blue region of Figure 25, is desirable feature for effective exciton dissociation and charge transfer. 


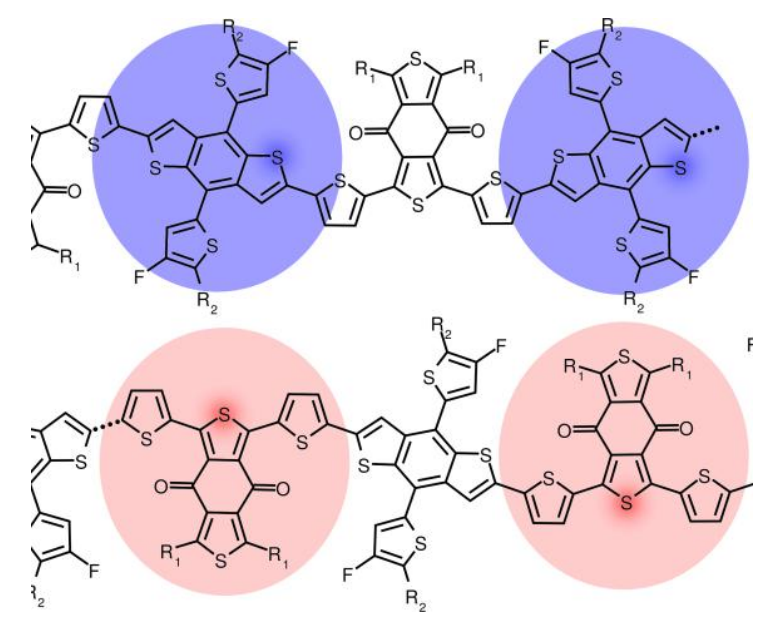

Figure 25. Reactive regions in relation to nucleophiles (bottom) and electrophiles (top). The most reactive sites are highlighted.

These interactions can be better evaluated via MD/ReaxFF calculations. For this purpose, a simulation box of $180 \times 180 \times 180 \AA^{3}$ with randomly distributed oligomers of PM6 (decamers) and molecules of Y6 was designed with the aid of Packmol computational package. $^{246}$ Ten decamers of PM6 and 50 molecules of Y6 were used to reproduce typical experimental D-A weight proportions (i.e., 1:1.2 w/w). The system was then let to evolve at room temperature in an NVT ensemble for 20 ps to evaluate the most relevant PM6-Y6 interactions. Periodic boundary conditions (PBC) were applied for all the directions. The calculations were performed using the ReaxFF force field, ${ }^{247,248}$ with the aid of LAMMPS computational package, ${ }^{249}$ considering a timestep of 0.05 fs. Figure 26 (Figure 27) shows the radial distribution of pairs, $\mathrm{g}(\mathrm{r})$, obtained by considering the interaction of each atom of PM6 (Y6) in relation to the atoms of Y6 (PM6).

For PM6 (Figure 26) it is noticed that: i) the carbon atoms tend to interact with the $\mathrm{H}$, $\mathrm{F}$ and $\mathrm{N}$ atoms of $\mathrm{Y} 6$; ii) fluorine interacts with $\mathrm{H}_{(\mathrm{Y} 6)}$ and $\mathrm{F}_{(\mathrm{Y} 6)}$; iii) hydrogens with $\mathrm{H}_{(\mathrm{Y} 6)}$ and $\mathrm{N}_{(\mathrm{Y} 6)}$; iv) oxygen only with $\mathrm{H}_{(\mathrm{Y} 6)}$; and v) sulfur only with $\mathrm{O}_{(\mathrm{Y} 6)}$. Very strong interactions are noticed for $\mathrm{H}_{(\mathrm{PM} 6)^{--}} \mathrm{N}_{(\mathrm{Y} 6)}$ and $\mathrm{S}_{(\mathrm{PM} 6)^{---}} \mathrm{O}_{(\mathrm{Y} 6)}$. The higher average distances observed for the $\mathrm{O}_{\text {(PM6) }}$ (Fig. 26d) in relation to $\mathrm{F}_{(\mathrm{PM} 6)}$ (Fig. 26b) indicates that $\mathrm{Y} 6$ tends to stay around the 
fluorinated thienyl benzodithiophene block (BDT, the blue block of Figure 25), which can be attributed to the repulsive forces between $\mathrm{CN}$ groups of $\mathrm{Y} 6$ and the oxygen atoms of PM6 (see MEPs in Figure 24). Interestingly the analysis of CAFI indicates that BDT block tends to interact with external electrophilic agents (i.e., with electron acceptors), which can explain the good performance of the PM6:Y6 systems in OPVs. 

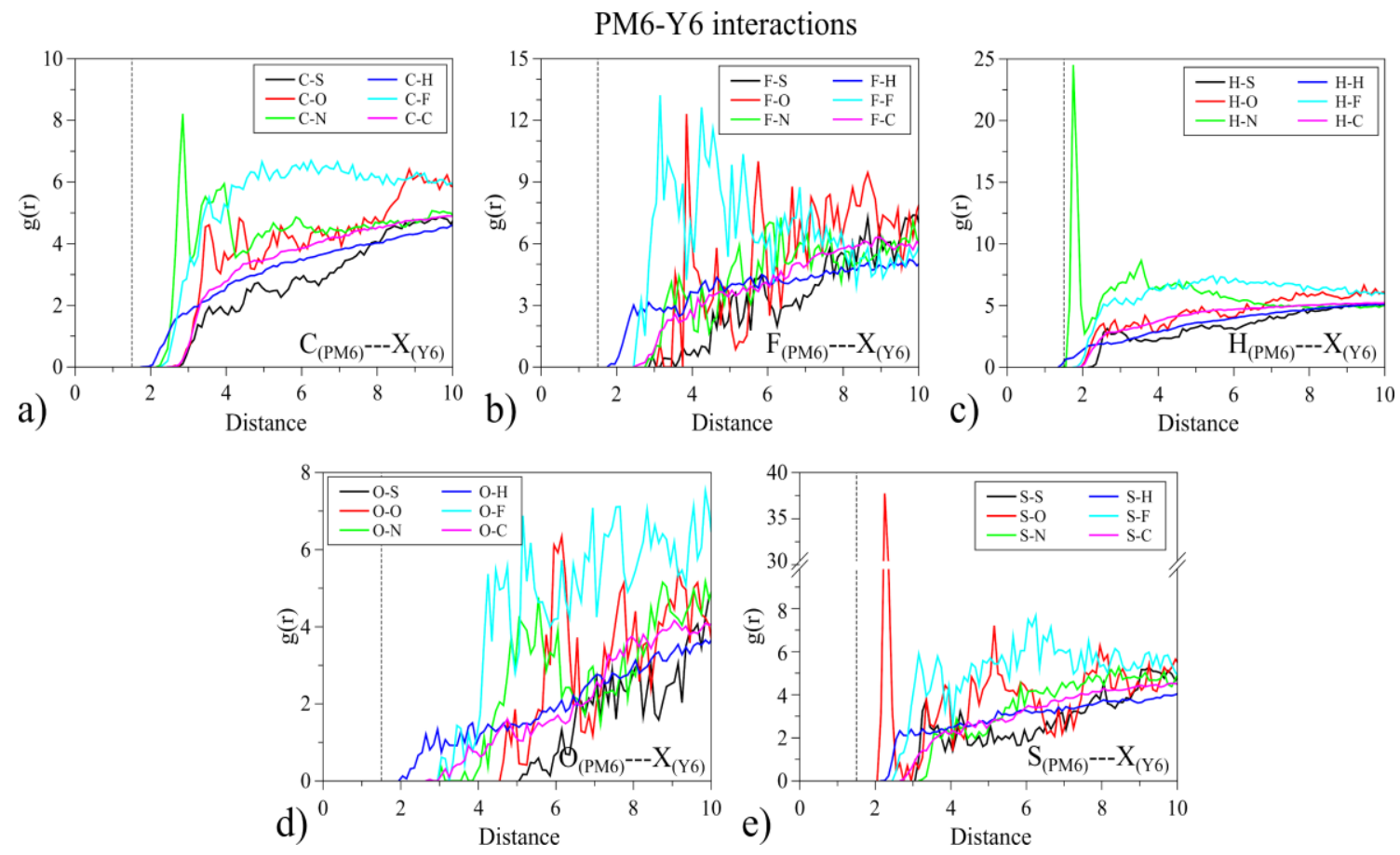

Figure 26 Radial pair distribution of the atoms of Y6 in relation to specific atoms of PM6.
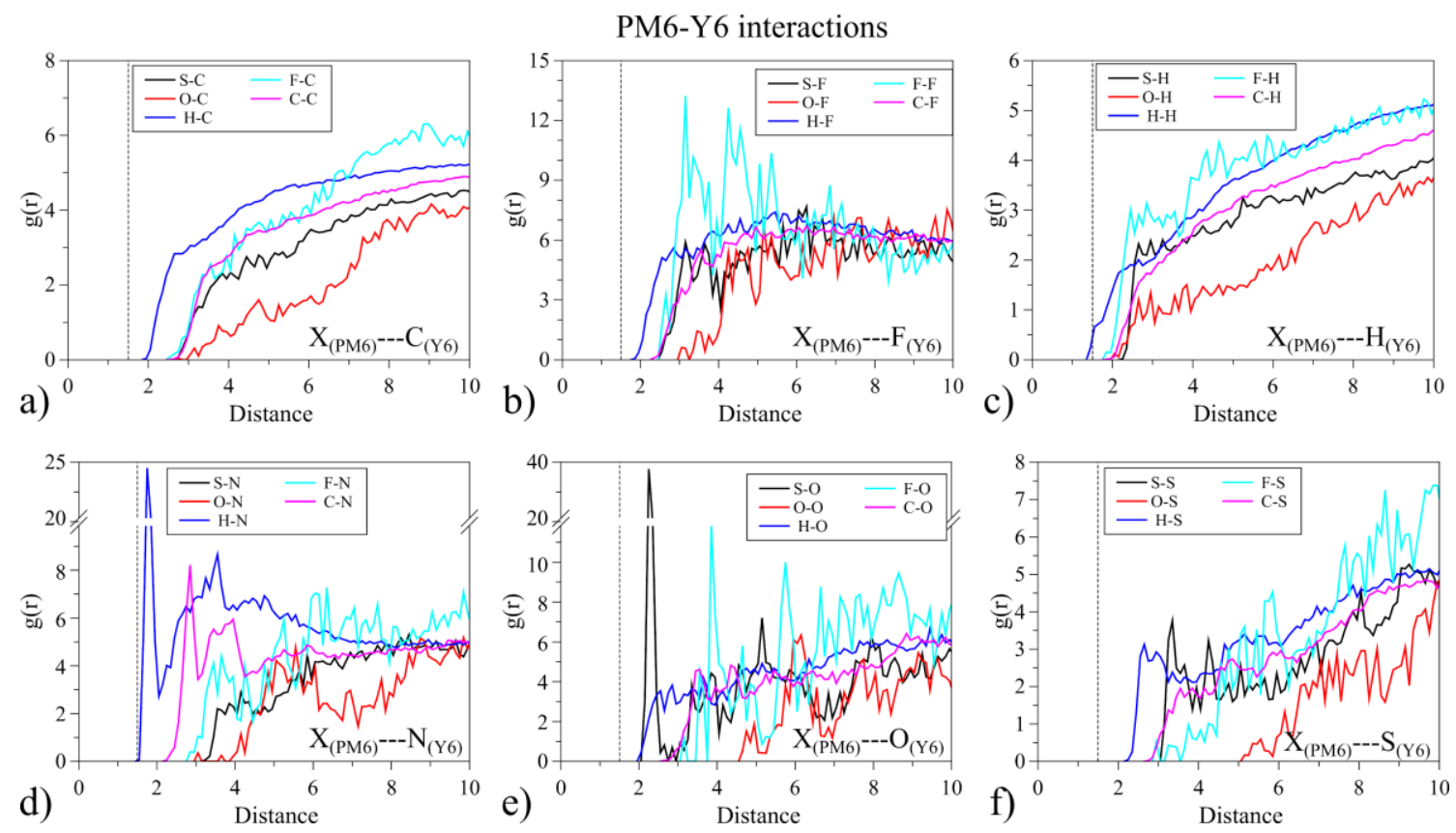

Figure 27. Radial pair distribution of the atoms of PM6 in relation to specific atoms of Y6.

For Y6 it is noticed that: i) the carbon, nitrogen and sulfur atoms tend to interact with the hydrogen atoms of PM6; ii) fluorines and hydrogens interact with $\mathrm{H}_{(\mathrm{PM} 6)}$ and $\mathrm{F}_{(\mathrm{PM} 6)}$; and 
iii) the oxygen tends to interact with $\mathrm{S}_{(\mathrm{PM} 6)}$ and $\mathrm{H}_{(\mathrm{PM} 6)}$. More effective approximations are noticed for $\mathrm{N}_{(\mathrm{Y} 6)^{---}} \mathrm{H}_{(\mathrm{PM} 6)}$ and $\mathrm{O}_{(\mathrm{Y} 6)^{---}} \mathrm{S}_{(\mathrm{PM} 6)}$. The following order of average positions $\mathrm{N}_{(\mathrm{Y} 6)^{---}}$ $\mathrm{H}_{(\mathrm{PM} 6)}<\mathrm{N}_{(\mathrm{Y} 6)^{---}} \mathrm{C}_{(\mathrm{PM} 6)}<\mathrm{N}_{(\mathrm{Y} 6)^{---}} \mathrm{F}_{(\mathrm{PM} 6)}<\mathrm{N}_{(\mathrm{Y} 6)^{---}} \mathrm{O}_{(\mathrm{PM} 6)}$ suggests that the Y6-PM6 interactions are governed by the side chains, especially involving $\mathrm{CN}$ groups (Y6) and side carbon chains of the BDT (PM6). For this reason the existence of high reactivity in relation to nucleophiles $\left(\mathrm{f}^{+}\right)$at $\mathrm{CN}$ group of $\mathrm{Y} 6$ and intermediary reactivity on the fluorinated thienyl group of PM6 (Figure 24) are supposed to play a relevant role in the charge transfer process of PM6:Y6 based devices.

A number of additional information could be provided from similar DFT/MD based studies. For instance, the definition of effective percolative pathways for subsequent charge transport simulations, evaluation of degradation processes and their effects in the charge transport, the role of the movement of ions on the performance of the devices, the effect of changes induced on the total density of states of the systems during the charge transport, charge accumulation effects, etc. highlighting the relevance of such combined studies for the evaluation and engineering of new compounds to be employed in OPVs.

\section{Conclusion}

The pure sense of ingenuity and development that has occurred over the last 35 years in organic photovoltaics is astounding. The pace has sometimes been slow, simply because the complexities facing this field are cliff-like. However, the fundamentals of the subject, that semi-conductors do deliver photo-electricity, and that their unlimited variability in structures mean that, eventually, this field will continue to keep delivering higher efficiencies. Finally, we might find that OPVs are more widely used than silicon or other types of devices, simply because of their adaptability to morph to building designs in terms of colours and shapes. Their non-toxicity makes them politically more acceptable than perovskites. This 
development, though, needs a certain patience and nerve on the part of investors and referees; the road will always require considerable work, but the inventiveness we have seen in this short review will we hope be infectious.

One subject that we have not covered but can be mentioned here is the scaling up of devices to large modules, of several tens of $\mathrm{cm}^{2}$ areas and greater. For this field really does show that OPV means business. For example the work by Brabec and colleagues is inspiring in making efficient modules, with exceptional geometric fill factors ${ }^{250}$ and efficiencies greater than $12.6 \% .^{251}$ Aiding this work will be developments in modelling to select efficient materials, and also to use machine learning for processing, further accelerating developments in industry. ${ }^{252}$ In industry itself, the reliability, colour fastness and applicability of OPV to buildings is constantly developing at a surprising pace ${ }^{253}$ with large installations being made. As OPVs go more and more into the market place it is probable that education and working with communities, to both explain the technology, and to benefit from local and school initiatives and the feedback from those actions, will start to become more important, much as occurred in the 1980 s with the introduction of computers. In our work, ${ }^{254}$ at this level, the introduction of very large sites made it clear that not only efficiency, but stability, aesthetics, legalities, safety, non-toxicity, recyclability and are all important factors. These elements will all favour the long-term development of OPV. 


\section{References}

1 Office of Science; U.S. Department of Energy, Basic Research Needs for Solar Energy Utilization, 2005, https://science.osti.gov/-

/media/bes/pdf/reports/files/Basic_Research_Needs_for_Solar_Energy_Utilization_rpt.pdf [accessed 3 December 2020].

2 Hong L, Yao H, Cui Y, Ge Z and Hou J, APL Mater. 8: 120901 (2020).

3 Espinosa N, Hösel M, Angmo D and Krebs FC, Energy Environ Sci. 5: 5117-5132 (2012).

4 van der Wiel B, Egelhaaf H-J, Issa H, Roos M and Henze N, MRS Proceedings, 1639 (2014), doi:10.1557/opl.2014.88.

5 Subramaniam SV, Kutsarov D, Sauermann T and Meier SB, Energy Technol 2000234 (2020).

$6 \quad \mathrm{Xie} \mathrm{Y}$ and Wu H, Materials Today Advances, 5: 100048 (2020).

7 Topham P D, Parnell AJ and Hiorns RC, J Polym Sci Pt B: Polym Phys 49(16): 1131-1156 (2011).

8 Liu X, Rand BP and Forrest SR, 1(9): 815-829 (2019).

9 Hughes MP, Rosenthal KD, Ran NA, Seifrid M, Bazan GC and Nguyen T-Q, Adv Funct Mater. 28: 1801542 (2018).

10 Alvarado SF, Seidler PF, Lidzey DG and Bradley DDC, Phys Rev Lett 81: 1082 (1998).

11 Li S, Liu W, Li C-Z, Shi M, Chen H, Small 13: 1701120 (2017).

12 Tang CW, Appl Phys Lett 48: 183-185 (1986).

13 Scharber MC, Muhlbacher D, Koppe M, Denk P, Waldauf C, Heeger AJ and Brabec CJ Adv Mater 18:789-794 (2006).

14 Luyao Lu L, Zheng T, Wu Q, Schneider AM, Zhao D and Yu L, Chem Rev, 115(23): 12666-12731 (2015).

15 Sorrentino R, Kozma E, Luzzati S and Po R, Energy Environ Sci 14: 180-223 (2021).

16 Lattante S, electronics 3: 132-164 (2014).

17 Xu H, Yuan F, Zhou D, Liao X, Chen L and Chen Y, J Mater Chem A 8: 11478-11492 (2020).

18 Gueye MN, Carella A, Faure-Vincent J, Demadrille R and Simonato J-P, Progress in Materials Science 108: 100616 (2020).

19 Lopez SA, Sanchez-Lengeling B, Goes Soares J de, Asuru-Guzik A, Joule 1: 857-870 (2017).

20 Sariciftci NS, Smilowitz L, Heeger AJ and Wudl F, Science 258: 1474-1476 (1992).

Kroto HW, Heath JR, O'Brien SC, Curl RF and Smalley RE, Nature 318: 162-163 (1985).

Glenis S, Horowitz G, Tourillon G and Garnier F, Thin Solid Films 111: 93-103 (1984).

Yu G, Gao J, Hummelen JC, Wudl F and Heeger AJ, Science, 70: 1789-1791 (1995).

Scharber MC and Sariciftci NS, Prog Polym Sci, 38(12): 1929-1940 (2013).

Günes S, Neugebauer H and Sariciftchi NS, Chem Rev, 107(4): 1324-1338 (2007).

Blayney AJ, Perepichka IF, Wudl F, Perepichka DF, Israel J Chem, 54: 674-688 (2014).

Sariciftci NS, Braun D, Zhang C, Srdanov VI, Heeger AJ, Stucky and Wudl F, Appl Phys Lett, 62:585(1993).

28 Chambon S, Rivaton A, Gardette J-L and Firon M, Solar Energy Materials and Solar Cells, 91(5):395 (2007).

29 Shaheen SE, Brabec CJ, Sariciftci NS, Padinger F and Fromherz T, Appl Phys Lett 78:841-843 (2001).

30 Brabec CJ, Sariciftci NS and Hummelen JC, Adv Funct Mater 11:15-26 (2001).

31 Kuhn, W. Helv. Chim. Acta. 31: 1780 (1948).

32 Moliton A and Hiorns RC, Polm Int 53(10): 1397-1412 (2004).

Zoombelt AP, Leenen MAM, Fonrodona M, Nicolas Y, Wienk MM and Janssen RAJ Polymer 50: 45649 (2009).

34 McCulloch I, Ashraf RS, Biniek L, Bronstein H, Combe C, Donaghey JE, James DI, Nielsen CB, Schroeder BC and Zhang W, Acc Chem Res 45:714-722 (2012).

35 Chochos CL and Choulis SA, Prog Polym Sci 36(10): 1326-1414 (2011).

36 a) Osaka I and McCullough RD, Acc Chem Res 41(9) 1202-1214 (2008); b) Hiorns RC, de Bettignies R, Leroy J, Bailly S, Firon M, Sentein C, Khoukh A, Preud'homme H and Dagron- Lartigau C, Adv Funct Mater 16(17): 2263-2273.

37 Dang MT, Hirsch L and Wantz G, Adv Mater 23(31): 3597-3602 (2011).

38 Payerne R, Brun M, Rannou P, Baptist R and Grévin B, Synthetic Metals 146(3): 311-315 (2004).

39 Kim Y, Choulis SA, Nelson J and Bradley DDC, Appl Phys Lett 86: 063502 (2005).

40 Lee JK, Ma WL, Brabec CJ, Yuen J, Moon JS, Kim JY, Lee K, Bazan GC and Heeger AJ J Am Chem Soc 130: 3619-3623 (2008).

41 Doumon NY, Wang G, Qiu X, Minnaard AJ, Chiechi RC and Koster LJA, Scientific Reports, 9: 4305 (2019).

42 Tournebiz, A, Rivaton A, Peisert H and Chassé T, Phys Chem C 119: 9142-9148 (2015).

43 Li G, Chang W-H and Yang Y, Nature Reviews Materials 2: 17043 (2017). 
Wakim S, Alem S, Li Z, Zhang Y, Tse S-C, Lu J, Ding J and Tao Y, J Mater Chem 21(29): 10920-10928 (2011).

Qian D, Ye L, Zhang M, Liang Y, Li L, Huang Y, Guo X, Zhang S, Tan Z and Hou J, Macromolecules 45(24): 9611-9617 (2012).

Meng L, Zhang Y, Wan X, Li C, Zhang X, Wang Y, Ke X and Xiao Z, Science 361: 1094-1098 (2018). Liu Q, Jiang Y, Jin K, Qin J, Xu J, Li W, Xiong J, Liu J, Xiao Z, Sun K, Yang S, Zhang X and Ding L, Science Bulletin 64(4): 272-275 (2020).

Jin K, Xiao Z and Ding L, Journal of Semiconductors, 42(1): 010502 (2021).

Cui Y, Yao H, Zhang T, Hong L, Gao B, Xian K, Qin J and Hou J, Adv Mater 31(42): 1904512 (2020). Roquet S, Cravino A, Leriche P, Alévêque A, Frère P and Roncali J, J Am Chem Soc 128: 3459 (2006). Roncali J, Leriche P and Cravino A, Adv Mater 19: 20145-2060 (2007).

Liu S-Y, Jung JW, Li C-Z, Huang J, Zhang Chen H and Jen AK-Y, J Mater Chem A 44: 22162-22169 (2015).

Sun Y, Welch GC, Leong WL, Takacs CJ, Bazan GC and Heeger AJ, Nat Mater 11: 44 (2011).

Zhou J, Zuo Y, Wan X, Long G, Zhang Q, Ni W, Liu Y, Li Z, He G, Li C, Kan B, Li M, Chen Y, J Am Chem Soc 135: 8484 (2013).

Ilmi R, Haque A and Khan MS, Organic Electronics 58: 53-62 (2018),

Zhou R, Zhaoyon H, Yang C, Yu J, Feng J, Adil MA, Deng D, Zou W, Zhang J, Lu K, Ma W, Gao F and Wei Z, Nature Commun 10: 5393 (2019).

Tessler N, Preezant Y, Rappaport N and Roichman Y, Adv Mater, 21: 2741-2761 (2009).

Fratini S, Nikolka M, Salleo A, Schweicher G and Sirringhaus H, Nat Mater, 19: 491-502 (2020).

Hummelen JC, Knight BW, LePeq F, Wudl F, Yao J and Wilkins CL, J Org Chem 60:(3) 532-538 (1992).

Takehara H, Fujiwara M, Arikawa M, Diener MD and Alford JM, Carbon 43(2): 311-319 (2005).

Scott LT, Boorum MM, McMahon BJ, Hagen S, Mack J, Blank J, Wegner H and de Meijere A, Science 295(5559): 1500-1503 (2002).

H J and Guo X, Active Layer Materials for Organic Solar Cells. In: Choy W (ed) Organic Solar Cells. Green Energy and Technology. London: Springer, 2012; 17-42.

Wöbkenberg PH, Bradley DDC, Kronholm D, Hummelen JC, de Leeuw DM, Cölle M and Anthopoulos TD, Synth Met 158:468-472 (2008).

Faist MA, Shoaee S, Tuladhar S, Dibb GFA, Foster S, Gong W, Kirchatz T, Bradley DDC, Durrant JR and Nelson J, Adv Energy Mater, 3(6): 744-752 (2013).

Collavini S and Delgado JL, Sustainable Energy \& Fuels, 2: 2480-2493 (2018).

Elumalai NK and Uddin A, Energy Environ. Sci. 9: 391-410 (2016).

Hofinger J, Putz C, Mayr F, Gugujonovic K, Wieland D and Scharber MC, Mater Adv, (2021).

DOI: $10.1039 / \mathrm{d} 1 \mathrm{ma} 00293 \mathrm{~g}$

Campoy-Quiles M, Ferenczi T, Agostinelli T, Etchegoin PG, Kim, Y, Anthropoulos TD, Stavrinou PN, Bradley DDC and Nelson J, Nature Materials 7:158-164 (2008).

Dowland SA, Salvador M, Perea JD, Gasparini N, Langer S, Rajoelson S, Ramanitra HH, Linder BD, Osvet A, Brabec CJ, Hiorns RC and Egelhaaf H-J, ACS Appl Mater Interfaces 9(12): 10971-10982 (2017).

Salvador M, Gasparini N, Prea JD, Paleti SH, Distler A, Inasaridze LN, Troshin PA, Lüer L, Egelhaaf H-J and Brabec C, Energy Environ Sci 10: 2005-2016 (2017).

Energy and Electron Transfer in Photo-and Electro-Active Fulleren Dyads, P. Hudhomme and R. M. Williams, in Handbook of Carbon Nano Materials, 2011, pages 545-591, World Scientific Series on Carbon Nanoscience. DOI: 10.1142/9789814327824_0017

2 Baffreau J, Leroy-Lhez S, Van Anh N, Williams RM and Hudhomme P, Chemistry A European Journal, 14: 4974-4992 (2008).

Gégout A, Delgado JL, Nierengarten J-F, Delavaux-Nicot B, Listorti A, Chioboli C, Belbraka A and Armaroli N, New Journal of Chemistry, 33: 2174-2182 (2009).

Doumon NY, Houard FV, Dong J, Christodoulis P, Dryzhov MV, Portale G and Koster LJA, J Mater hem C 7: 5104 (2019).

6 Ramanitra HH, Dowland SA, Bregadiolli BA, Santos Silva H, Bégué D, Graeff CFO, Peisert H, Chassé T, Rajoelson S, Salvador M, Osvet A, Brabec CJ, Egelhaaf H-J, Morse G, Distler A and Hiorns RC, ACS Applied Materials \& Interfaces, 9: 10971 (2017).

77 Santos Silva H, Ramanitra HH, Bregadiolli BA, Bégué D, Graeff CFO, Dagron-Lartigau C, Peisert H, Chassé T, Hiorns RC, J Polym Sci Pt A, 55: 1345-1355 (2017).

Stephen M, Dowland S, Gregori A, Ramanitra HR, Santos Silva H, Combe CMS, Bégué D, DagronLartigau C, Genevičius K, Arlauskas K, Juška G, Distler A and Hiorns RC, Polym Int 66: 388-398 (2017). 
Stephen M, Ramanitra HH, Santos Silva H, Dowland S, Bégué D, Genevičius K, Arlauskas K, Juška G, Morse GE, Distler A and Hiorns RC, 52: 6107-6110 Chem Comm (2016).

Ramanitra HH, Santos Silva H, Bregadiolli BA, Khoukh A, Combe CMS, Dowland SA, Bégué D, Graeff CFO, Dagron-Lartigau C, Distler A, Morse G and Hiorns RC Macromolecules 49(5): 1681-1691 (2016). Cardon CM, Li W, Kaifer AE, Stockdale D and Bazan GC, Adv Mater 23: 2367-2371 (2011).

Rahbeh R, Parbaile M, Chakaroun M, Ratier B, Aldissi M and Moliton A, Polym Int 59(11): 1514-1519 (2010).

Bronstein H, Nielson CB, Schroeder BC and McCulloch I, Nature Reviews Chemistry 4: 66-77 (2020).

Wadsworth A, Moser M, Marks A, Little MS, Gasparini N, Brabec CJ, Baran D and McCulloch C, Chem Soc Rev 48: 1596-1625 (2019).

Zhang G, Zhao J, Chow PCY, Jiang K, Zhang J, Zhu Z, Zhang J, Huang F and Yan H, Chem Rev, 118(7): 3447-3507 (2018).

Liu X, Li Y, Ding K and Forrest S, Phys Rec Applied, 11: 024060 (2019).

Mao Z, Senevirathna W, Liao J-Y, Gu J, Kesava SV, Guo C, Gomez ED and Sauvé G, Adv Mater 26, 6290-6294 (2014).

Winzenberg KN, Kemppinen P, Scholes FH, Collis GE, Shu Y, Birendra Singh T, Bilic A, Forsyth CM Watkins SE, Chem Commun 49: 6307-6309 (2013).

Forti G, Nitti A, Osw P, Bianchi G, Po R and Pasini D, Int J Mol 21: 8085 (2020).

Lin Y, Wang J, Zhang Z-G, Bai H, Li Y, Zhu D and Zhan X, Adv Mater 27:1170 (2015).

Zhao W, Qian D, Zhang S, Li S, Inganäs O, Gao F and Hou J, Adv Mater 28: 4734 (2016).

Zhang S, Qin Y, Zhu J and Hou J, Adv Mater 30: 1800868 (2018).

Meng L, Zhang Y, Wan X, Li C, Zhang X, Wang Y, Ke X and Xiao Z, Science 361: 1094-1098 (2018).

Avalos-Quiroz YA, Bardagot O, Kervella Y, Aumaître C, Cabau L, Rivaton A, Margeat O, Videlot-

Ackermann, C, Vongsaysy U, Ackermann J, Demadrille R, ChemSusChem, earlyview, doi:

10.1002/cssc.202101005

Xie G, Zhang Z, Su Z, Zhang X, Zhang J, Nano Energy 69: 104447 (2020).

Yuan J, Zhang Y, Zhou L, Zhang G, Yip H-L, Lau T-K and Zou Y, Joule 3(4):1140-1151 (2019).

97 Wang J and Zhan X, Trends in Chemistry, 1(9): 869-881 (2019).

98 Josse P, Li S, Dayneko S, Joly D, Labrunie A, Dabos-Seignon S, Allain M, Siegler B, Demadrille R, Welch GC, Risko C, Blanchard P and Cabanetos C, J Mater Chem C 6(4) 761-766 (2018).

99 Dalinot C, Marqés PS, Castán JMA, Josse P, Allain M, Galán LA, Monnereau C, Maury O, Blanchard P and Cabanetos C, Eur J Org Chem 2020(14): 2140-2145 (2020).

100 Halls JJM, Walsh CA, Greenham NC, Marseglia EA, Friend RH and Moratti SC, Nature, 376: 498500 (1995).

101 Yu G and Heeger AJ, J Appl Phys 78: 4510-4515 (1995).

102 Glossary of terms relating to electronic, photonic and magnetic properties of polymers (IUPAC Recommendations 2020), Vohlídal J, Graeff CFO, Hiorns RC, Jones RG, Luscombe C, Schué F, Stingelin N and Walter MG Pure Appl Chem (submitted 2020).

103 Li Y, Gu M, Pan Z, Zhang B, Yang X, Gu J and Chen Y, J Mater Chem A 5: 10798-10814 (2017).

104 Liang C and Wang H, Organic Electronics, 50: 443-457 (2017).

105 Alam MM and Jenekhe SA Chem Mater 16(23): 4647-4656 (2014).

106 Lee J, Kalin AJ, Yuan T, Al-Hashimi M and Fang L, Chem Sci 8(4): 2503-2521 (2017).

107 Yan H, Chen Z, Zheng Y, Newman C, Quinn JR, Dötz F, Kastler M and Facchetti A, Nature 457: 679686 (2009).

108 Gao L, Zhang Z-G, Xue L, Min J, Zhang J, Zei Z and Li Y, Adv Mater 28(9): 1884-1890 (2016).

109 Lee J-W, Choi N, Kim D, Ngoc-Lan Phan T, Kag H, Kim T-S and Kim BJ, Chem Mater 33(3): 10701081 (2021).

110 Sun H, Yu H, Shi Y, Yu J, Peng Z, Zhang X, Liu B, Wang J, Singh R, Lee J, Li Y, Wei Z, Liao Q, Kan, Z, Ye L, Yan H, Gao F and Guo X, Adv Mater 32: 2004183 (2020).

111 Stalder R, Mei J, Graham KR, Estrada LA and Reynolds JR, Chem Mater 26: 664-678 (2013);

112 Randell NM and Kelly TL, The Chemical Record, 19(6): 973-988 (2018).

113 Zheng N, Mahmood K, Zhong W, Liu F, Zhu P, Wang Z, Xie B, Chen Z, Zhang K, Ying L, Huang F and Cao Y, Nano Energy 58: 724-731 (2019).

114 Fu, H, Li Y, Yu J, Wu Z, Fan Q, Lin F, Woo HY, Gao F, Zhu Z and Jen AKY, J Am Chem Soc 143(7): 2665-2670 (2021).

115 Yin H, Yan C, Hu H, Ka Wai Ho, J, Zhan X, Li G and So SK, Materials Science and Engineering: R: Reports, 140: 100542 (2020). 
Ma X, An Q, Ibraikulov OA, Lévêque P, Heiser T, Leclerc N, Zhang X and Zhang F, J Mater Chem A, 8: 1265-1272 (2020).

117 Yin H, Yan C, Hu H, Ka Wai Ho, J, Zhan X, Li G and So SK, Materials Science and Engineering: R: Reports, 140: 100542 (2020).

118 Marzano G, Ciasca CV, Babudri F, Bianchi G, Pellegrino A, Po R and Farinola GM, European Journal of Chemistry, 30: 6583-6614 (2014).

119 Yokozawa T and Ohta Y, Chapter 1: Controlled Synthesis of Conjugated Polymers in Catalyst-transfer Condensation Polymerization: Monomers and Catalysts, in Semiconducting Polymers: Controlled Synthesis and Microstructure 1-37 (2016) DOI: 10.1039/9781782624004-00001, From Book Series: Polymer Chemistry Series. Okamoto K and Luscombe CK, Polym Chem 2: 2424-2434 (2011). Pankow RM and Thompson BC, Polymer Chemistry 11:630-640 (2020). Levitsky A, Matrone GM, Khirbat A, Bargigia I, Chu X, Nahor O, Segal-Peretz T, Moulé AJ, Richter LJ, Silva C, Stingelin N and Frey GL, Advanced Science, 7: 2000960 (2020). Liu D, Yang L, Wu Y, Wang X, Zeng Y, Han G, Yao H, Li S, Zhang S, Zhang Y, Yi Y, He C, Ma W and Hou J, Chem Mater 30(3) 619-628 (2018).

Savikhin V, Babics M, Neophytou M, Liu S, Oosterhout SD, Yan H, Gu X, Beaujuge PM and Toney MF, Chem Mater 30(21) 7872-7884 (2018). Jiang K, Wei Q, Lai JYL, Peng Z, Kim HK, Yuan J , Ye L, Ade H, Zou Y and Yan H, Joule 3(12): 30203033 (2019).

Zhang Y, Yao H, Zhang S, Qin Y, Zhang J, Yang L, Li W, Wei Z, Gao F and Hou J, Sci China-Chem 61: 1328-1337 (2018).

Ji Z, Xu X, Zhang G, Li Y and Peng Q, Nano Energy 40: 214-223 (2017).

Chen H, Hu Z, Wang H, Liu L, Chao P, Qu J, Chen W, Liu A and He FA Joule 2: 1623-1634 (2018). Chen HY, Hou J, Zhang S, Liang Y, Yang G, Yang Y, Yu L, Wu Y and Li G, Nat Photonics 3: 649-653 (2009). (2019).

Deng Y, Li W, Liu L, Tian H, Xie Z, Geng Y and Wang F, Energy \& Environmental Science, 8: 585-591 (2015).

Kirova N, Polym Int 57(5): 678-688 (2008).

Mikhnenko OV, Blom PWM and Nguyen T-Q, Energy Environ Sci 8: 1867 (2015).

Nunzi JM, Comptes Rendus Phys 3: 523-542 (2002).

Westacott P, Tumbleston JR, Shoaee S, Fearn S, Bannock JH, Gilchrist JB, Heutz S, DeMello J, Heeney M, Ade H, Durrant J, McPhail DS and Stingelin N, Energy \& Environmental Science 6: 2756-2764

Ma WL, Yang CY, Gong X, Lee KH and Heeger AJ, Adv Funct Mater 15:1617-1622 (2005).

Peet J, Kim JY, Coates NE, Ma WL, Heeger AJ, Moses D and Bazan GC, Nat Mater 6:497-500 (2007).

Treat ND, Reif OG, Fearn S, Rumbles G, Hawker CJ, Chabinyc ML and Stingelin N, ACS appl Energy Mater 1:1973-1980 (2018).

Li G, Shrotriya V, Huang J, Yao Y, Moriarty T, Emery K and Yang Y, Nat Mater 4: 864-868 (2005). van Bavel SS, Bärenklau M, de With G, Hoppe H and Loos J, Adv Funct Mater 20: 1458-1463 (2010). Kesavan AV, Rao AD and Ramamurthy PC, ACS Appl Mater Interfaces 9(34): 28774-28784 (2017). Xiao T, Xu H, Grancini G, Mai J, Petrozza A, Jeng U-S, Wang Y, Xin X, Lu Y, Choon NS, Xiao H, Ong BS, Lu X and Zhao N, Sci. Rep 9(4): 5211 (2014).

Sun SS, Solar Energy Materials and Solar Cells 79: 257-264 (2003).

Sun S, Fan Z, Wang Y and Haliburton J, J Mater Sci, 40: 1429-1443 (2005).

Hiorns RC, Iratcabal P, Begue D, Khoukh A, De Bettignies R, Leroy J, Firon M, Sentein C, Martinez H, Preud'homme H and Dagron-Lartigau C, J Polym Sci Pt A: Polym Chem 47: 2304-2317 (2009).

Lindner S, Huttner S, Chiche A, Thelakkat M and Krausch G, Angew Chem Int Ed, 45: 3364 (2006).

Mitchell VD and Jones DJ, Polym Chem, 2(4): 470-489 (2018).

Nakabayashi K and Mori H, Materials (Basel), 7(4): 3274-3290 (2014).

Roncali J and Grosu I, Adv Sci (Weinh) 6(1): 1801026 (2019).

Tseng Y-C and Darling SB, Polymers 2(4): 470-489 (2010).

de Cuendias A, Hiorns RC, Cloutet E, Vignau L and Cramail H, Polym. Int. 59: 1452-1476 (2010). van der Veen M H, de Boer B, Stalmach U, van de wetering KI and Hadziioannou G, Macromolecules 37: 3673-3684 (2004).

Zhang QL, Cirpan A, Russell TP and Emrick T, Macromolecules 42: 1079-1082 (2009). 

(2018).

163 Yu P, Feng G, Li J, Li C, Xu Y, Xiao C and Li W, J Mater Chem C 8: 2790 (2020)

164 Su Y-A, Maebayashi N, Fujita H, Lin Y-C, Chen C-I, Chen W-C, Michinobu T, Chueh C-C and Higashihara T, ACS Applied Materials \& Interfaces 12(10): 12083-12092 (2020).

165 Organic Solar Cells Materials, Devices, Interfaces, and Modeling Edited By Qiquan Qiao, $1^{\text {st }}$ Edition (2015), Boca Raton, CRC Press; Development of Solar Cells, Theory and Experiment, $1^{\text {st }}$ Edition, Springer in the Series: Challenges and Advances in Computational Chemistry and Physics Editors: Roy

JK, Kar S and Leszczynski J (2021).

166 Brédas J-L, Norton JE, Cornil J and Coropceanu V, Acc Chem Res 42:1691-1699 (2009).

167 Kippelen B and Brédas J-L, Energy \& Environmental Science, 2: 251-261 (2009).

168 Springborg M. Methods of electronic-structure calculations: from molecules to solids. John Wiley \& Sons, Chichester, pp 501 (2000).

169 Lewars E. Computational chemistry: introduction to the theory and applications of molecular and quantum mechanics, 2nd edn. Springer, Dordercht, pp 664 (2011).

170 Jensen F. Introduction to computational chemistry, 3th edn. John Wiley \& Sons, Chichester, pp 638 (2017).

171 Levine IN. Quantum Chemistry, 5th edn. Prentice Hall, New Delhi, pp. 739 (2006).

172 Rapaport DC. The Art of Molecular Dynamics Simulation, 2nd Ed. Cambridge University Press, Cambridge, pp 549 (2004).

173 Frenkel D and Smit B. Understanding molecular simulation: from algorithms to applications. Academic Press, San Diego, pp 638 (2002).

174 Doan D-H, Glitzky A and Liero M, Zeitschrift für Angewandte Mathematik und Physik, 70: 55 (2019).

175 Firdus Y and Anthopoulos TD, Chapter 8: Device Physics in Organic Solar Cells and Drift-Diffusion Simulations, in Soft-Matter Thin Film Solar Cells, Physical Processes and Device Simulation, Eds Ren J and Kan Z, AIP Publishing (2020). Neupane U, Bahrami B, Biesecker M, Baroughi MF and Qiao Q, Nano Energy 35:128-137 (2017).

Solar RRL 4(6): 2000029 (2020).

178 Groves C and Greenham NC (2013) Monte Carlo Simulations of Organic Photovoltaics. In: Beljonne D and Cornil J (eds) Multiscale Modelling of Organic and Hybrid Photovoltaics. Topics in Current Chemistry, vol 352. Springer, Berlin, Heidelberg. Casalegno M, Bernardi A and Raos G, J Chem Phys 139: 024706 (2013). Thongprong N and Duxbury PM, J Appl Phys 129: 083104 (2021).

Cui Y, Zhu P, Liao X, and Chen Y, J Mater Chem C 8: 15920-15939 (2020).

Roy RK, Pal S and Hirao K, J Chem Phys 110: 8236-8245 (1999).

Wang J-L and Mahmood A. Machine learning for high performance organic solar cells: current scenario and future prospective. Energy \& Environmental Science 14: 90-105(2021).

Mondelli P, Boschetto G, Horton P N, Tiwana P, Skylaris C-K, Coles S J, Krompiec M and Morse G, Mater Horiz 7: 1062-1072 (2020).

Munshi J, Chien T, Chen W and Balasubramanian G, Soft Matter 16: 6743-6751 (2020).

Murad AR, Iraqi A, Aziz SB, Abdullah, SN and Brza, MA, Polymers 12: 2627 (2020).

Antono E, Matsuzawa NN, Ling J, Saal JE, Arai H, Sasago M and Fujii E, J Phys Chem A 124: 8330(2020).

Pan Q-Q, Zhao Z-W, Wu Y and Geng Y, J Mol Graphics Modell 94: 107488 (2020). Friederich P, Fediai A, Kaiser S, Konrad M, Jung N and Wenzel W, Adv Mater 31: 1808256 (2019).

Brédas J-L, Norton JE, Cornil J and Coropceanu V, Acc Chem Res 42:1691-1699 (2009).

Swick Sm, Gebraad T, Jones L, Fu B, Aldrich TJ, Kohlstedt KL, Shatz GC, Facchetti A and Marks TJ, ChemPhysChem 20(20): 2608-2626 (2019).

Raheem AA, Kumar C, Shanmugam R, Murugan P and Praveen C, J Mater Chem C 9:4 562-4575 (2021). 
Feng J, Wang H, Rujisamphan N and Li Y, Front Chem 580252 (2020). Li Y Acc Chem Res 45(5): 723733 (2012).

Oliveira EF, Silva LC and Lavarda FC, Structural Chemistry 28 :1133-1140 (2017).

Alves GGB, Oliveira EF, Batagin-Neto A and Lavarda FC, Computational Materials Science 152: 12-19 (2018).

Zhou H, Yang L and You W, Macromolecules 45: 607-632 (2012).

Haddon RC, Acc Chem Res 21(6) 243-249 (1988). Sabalot-Cuzzubbo, J, Salvato-Vallverdu G, Bégué D and Cresson J, J Chem Phys 152: 244310 (2020).

Zhang C, Vadiee E, King R and Honsberg C, Journal of Materials Research, 33(4): 414-423 (2018).

Silva HS, Domínguez IF, Perthué A, Topham PD, Bussière P-O, Hiorns RC, Lombard C, Rivaton A, D and Pépin-Donat B, J Mater Chem A, 4: 15647-15654 (2016).

Bégué D, Guille E, Metz S, Arnaud MA, Silva HS, Seck M, Fayon P, Dagron-Lartigau C, Iratcabal P and Hiorns RC, RSC Advances 6: 13653-13656 (2016).

Janssen RAJ and Nelson J, 25(13): 1847-1858 (2013).

Wildman J, Repišćák P, Paterson MJ and Galbraith I, J Chem Theory Comput 12(8): 3813-3824 (2016).

Galvelis R, Doerr S, Damas JM, Harvey MJ and Fabritiis, J Chem Inf Model 59(8): 3485-3493 (2019).

Do K, Ravva MK, Wag T and Brédas J-L, Chem Mater 29(1): 346-354 (2017).

Volpi R, Stafström S and Linares M, J. Chem Phys 142: 094503 (2015).

Cheung DL and Troisi A, J. Phys. Chem. C 114(48): 20479-20488 (2010).

McMahon DP, Cheung DL and Troisi A, J Phys Chem Lett 2(21): 2737-2741 (2011).

Yoa C, Peng C, Yang Y, Li L, Bo M and Wang J, J Mater Chem C, 6(18): 4912-4918 (2018)].

Tessler N, Preezant Y, Rappaport N and Roichman Y, Adv Mater 21(27):2741-2761 (2009).

Baranovski SD physica status solidi (b) - basic solid state physics, 251(3): 487-525 (2014).

Rühle V, Lukyanov A, May F, Schrader M, Vehoff T, Kirkpatrick J, Baumeier B and Andrienko D, $J$

Theory Comput 7(10): 3335-3345 (2011).

Howard IA, Etzold F, Laquai F and Kemerink M, Adv Energy Mater 4(9): 1301743 (2014).

Kaiser W, Popp J, Rinderie M, Albes T and Gagliardi Algorithms 11(4): 37 (2018).

Heiber MC, The Journal of Open Source Software, 5(53):2307 (2020).

Do K, Ravva MK, Wag T and Brédas J-L, Chem Mater 29(1): 346-354 (2017).

Volpi R and Linares Chem Modell, 13: 1-26 (2017).

Hartke B and Grimme S, Phys Chem Chem Phys 17:16715-16718 (2015).

van Duin ACT, Dasgupta S, Lorant F and Goddard WA, J Phys Chem A 105: 9396-9409 (2001).

Qian H-J, van Duin ACT, Morokuma K and Irle S, J Chem Theory Comput 7: 2040-2048 (2011).

Paupitz R, Autreto PAS, Legoas SB, Srinivasan SG, van Duin, ACT and Galvão, DS, Nanotechnology 035706 (2013).

Flores MZS, Autreto PAS, Legoas SB and Galvao DS, Nanotechnology 20: 465704 (2009)

van Duin ACT, Strachan A, Stewman S, Zhang Q, Xu X and Goddard WA, J Phys Chem A 107: 38033811 (2003).

Zhang Q, Çağın T, van Duin ACT, Goddard WA, Qi Y and Hector LG, Phys Rev B: Condens Matter Mater Phys 69: 045423 (2004).

Chenoweth K, Cheung S, van Duin ACT, Goddard WA and Kober EM, J Am Chem Soc 127:7192-7202 (2005).

Raju M, Kim S-Y, van Duin ACT and Fichthorn KA, J Phys Chem C 117: 10558-10572 (2013).

Lascane LG, Oliveira EF, Galvão DS and Batagin-Neto A, Eur Polym J 141: 110085 (2020)

Lascane LG, Oliveira EF and Batagin-Neto A, MRS Advances 5: 497-503 (2020).

van Duin ACT. Reactive Force Fields: Concepts of ReaxFF. In: van Santen RA and Sautet P (eds) Computational Methods in Catalysis and Materials Science. Weinheim: Wiley-VCH Verlag GmbH and Co KgaA, 2009; 167-181.

Chenoweth K, Cheung S, van Duin ACT, Goddard WA and Kober EM, J Am Chem Soc 127:7192-7202 (2005).

Friederich P, Fediai A, Kaiser S, Konrad M, Jung N and Wenzel W, Adv Mater 31: 1808256 (2019).

Friederich P, Fediai A, Kaiser S, Konrad M, Jung N and Wenzel W, Adv Mater 31: 1808256 (2019).

Guo Q, Guo Q, Geng Y, Tang A, Zhang M, Du M, Sun X and Zhou E, Materials Chemistry Frontiers, 8: 3257-3280 (2021).

Yang W and Mortier WJ, J Am Chem Soc 108: 5708-5711 (1986).

Chirlian LE and Francl MM, J Comput Chem 8: 894-905 (1987).

Melin J, Aparicio F, Subramanian V, Galván M and Chattaraj PK, J Phys Chem A 108: 2487-2491 (2004).

Alves GGB, Lavarda FC, Graeff CFO and Batagin-Neto A, J Mol Graphics Modell 98: 107609 (2020).

Maia RA, Ventorim G and Batagin-Neto A, Journal of Molecular Modeling 25: 228 (2019). 
Geerlings P, de Proft F and Langenaeker W, Chem Rev 103: 1793-1874 (2003).

Domingo L, Ríos-Gutiérrez M and Pérez P, Molecules 21: 748 (2016).

240 Becke AD, J Chem Phys 98: 5648-5652 (1993).

241 Stephens PJ, Devlin FJ, Chabalowski CF and Frisch MJ, J Phys Chem 98: 11623-11627 (1994).

242 Vosko SH, Wilk L and Nusair M, Can J Phys 58: 1200-1211 (1980).

243 Lee C, Yang W and Parr R G, Phys Rev B: Condens Matter Mater Phys 37: 785-789 (1988).

244 Grimme S, Ehrlich S and Goerigk L, J Comput Chem 32: 1456-1465 (2011).

245 de Proft F, van Alsenoy C, Peeters A, Langenaeker W and Geerlings P, J Comput Chem 23: 1198-1209 (2002).

246 Martínez L, Andrade R, Birgin E G and Martínez JM, J Comput Chem 30: 2157-2164 (2009).

247 Kim S-Y, van Duin ACT and Kubicki JD, J Mater Res 28: 513-520 (2013).

248 Aktulga HM, Fogarty JC, Pandit SA and Grama AY, Parallel Computing 38: 245-259 (2012).

249 Plimpton S, J Comput Phys 117: 1-19 (1995).

250 Lucera L, Machui F, Kubis P, Schmidt HD, Adams J, Strohm S, Ahmad T, Forberich K, Egelhaaf H-J

and Brabec CJ, Energy \& Environmental Science 9: 89 (2016).

251 Distler A, Brabec CJ and Egelhaaf H-J, Progress in Photovoltaics Research and Applications 29: 24-31 (2021).

252 Du X, Lüer L, Heumüller T, Wagner J, Berger C, Osterrieder T, Wortmann J, Langner S, Vongsaysy U, Bertrand M, Li N, Stubhan T, Hauch J and Brabec CJ, Joule 5(2): 495-506 (2021).

253 Berny S, Blouin N, Distler A, Egelhaaf H-J, Krompiec M, Lohr A, Lozman OR, Morse GE, Nanson L, Pron A, Sauermann T, Seidler N, Tierny S, Tiwana P, Wagner M and Wilson H, Adv Sci 1500342 (2015).

254 Baylère P, Sauermann T, Meier S, Issa H and Hiorns RC, Large-scale community based organic photovoltaic installations, to be submitted. 